\title{
Novel Peptidomimetic Cysteine Protease Inhibitors as Potential Antimalarial Agents
}

Nicola Micale,", ${ }^{\#}$ Alan P. Kozikowski, ${ }^{\dagger}$ Roberta Ettari, ${ }^{\#}$ Silvana Grasso, ${ }^{\#}$ Maria Zappalà, ${ }^{\#}$ Jong-Jin Jeong, ${ }^{\S}$ Ajay Kumar, ${ }^{\ddagger}$ Manjit Hanspal, ${ }^{\ddagger}$ and Athar H. Chishti $^{\S}$

\begin{abstract}
${ }^{\# D i p a r t i m e n t o ~ F a r m a c o ~ C h i m i c o, ~ U n i v e r s i t y ~ o f ~ M e s s i n a, ~ V i a l e ~ A n n u n z i a t a, ~ 98168, ~ M e s s i n a, ~ I t a l y, ~}$ ${ }^{\dagger}$ Department of Medicinal Chemistry and Pharmacognosy, University of Illinois at Chicago, 833 South Wood Street, Chicago, Illinois 60612, ${ }^{\S}$ Department of Pharmacology, University College of Medicine, 909 South Wolcott Avenue, Chicago, IL 60612, 'Division of Cell Biology, Caritas St. Elizabeth's Medical Center, Boston, MA 02135 USA
\end{abstract}

Contents: ${ }^{1} \mathrm{H}$ NMR data for all compounds.

${ }^{13} \mathrm{C}$ NMR, MS, HRMS, $[\alpha]^{20}$ and elemental analyses for final compounds $\mathbf{1 7} \mathbf{a}-\mathbf{j}$ and most significant intermediates.

Experimental details for the synthesis of all compounds and biological assays.

*To whom correspondence should be addressed. Dipartimento Farmaco-Chimico, Viale Annunziata, 98168 , Messina, Italy. Tel: +39090 6766466. Fax: +39090 355613. E-mail: nmicale@ pharma.unime.it 


\section{Experimental Section}

General Procedures: Diethyl ether was distilled from phosphorus pentoxide; THF was freshly distilled under nitrogen from sodium benzophenone; dichloromethane was freshly distilled under nitrogen from calcium hydride.

The following abbreviations are used: ether $=$ Diethyl ether; $\mathrm{THF}=$ Tetrahydrofuran; $\mathrm{DMF}=$ $N, N$-Dimethylformamide; DMP = 2,2-Dimethoxypropane.

${ }^{1} \mathrm{H}$ NMR and ${ }^{13} \mathrm{C}$ NMR spectra were recorded on a Varian Unity Inova instrument at 300 $\mathrm{MHz}$ and $75 \mathrm{MHz}$, respectively. ${ }^{1} \mathrm{H}$ chemical shifts $(\delta)$ are reported in ppm downfield from internal TMS. ${ }^{13} \mathrm{C}$ chemical shifts are referenced to $\mathrm{CDCl}_{3}$ (central peak, $\delta=77.0 \mathrm{ppm}$ ) and to $\mathrm{CD}_{3} \mathrm{OD}$ (central peak, $\delta=49.0 \mathrm{ppm}$ ).

Mass spectra were measured in the EI or ESI mode at an ionization potential of $70 \mathrm{eV}$; HRMS experiment was performed on Q-TOF-2TM ( Micromass ).

TLC was performed on Merck silica gel $60 \mathrm{~F}_{254}$ glass plates; column chromatography was performed using Merck silica gel (60-200 mesh).

Elemental analyses were performed by Atlantic Microlab Inc., Atlanta, GA.

\section{(R)-2,2-Dimethyl-oxazolidine-3,4-dicarboxylic acid 3-tert-butyl ester 4-methyl ester (3)}

To a solution of D-serine methyl ester hydrochloride $2(3.0 \mathrm{~g}, 19.28 \mathrm{mmol})$ in aqueous $\mathrm{NaHCO}_{3} / \mathrm{THF}(8 / 2,30 \mathrm{~mL})$ was added $(\mathrm{Boc})_{2} \mathrm{O}(5.26 \mathrm{~g}, 24.10 \mathrm{mmol})$ and the reaction mixture was stirred at room temperature for $12 \mathrm{~h}$. The reaction mixture was poured in water and extracted with ethyl acetate $(2 \times 100 \mathrm{~mL})$. The extracts were combined, washed with water, dried, and concentrated under reduced pressure to get the product as crude $(4.06 \mathrm{~g}$, $96 \%)$

${ }^{1} \mathrm{H}$ NMR $\left(300 \mathrm{MHz}, \mathrm{CDCl}_{3}\right): \delta 5.53(\mathrm{~m}, 1 \mathrm{H}),, 4.39(\mathrm{~m}, 1 \mathrm{H}), 4.02-3.82(\mathrm{~m}, 2 \mathrm{H}), 3.79(\mathrm{~s}, 3 \mathrm{H})$, $2.78(\mathrm{~m}, 1 \mathrm{H}), 1.46(\mathrm{~s}, 9 \mathrm{H})$.

N-Boc D-serine methyl ester (4.06 g, $18.52 \mathrm{mmol})$ was dissolved in a mixture of acetone (60 $\mathrm{mL})$ and 2,2-DMP $(20 \mathrm{~mL})$ to which $\mathrm{BF}_{3} \cdot \mathrm{Et}_{2} \mathrm{O}(0.13 \mathrm{~mL})$ was added. The resulting solution 
was stirred at room temperature for $2 \mathrm{~h}$, after which time TLC showed no remaining starting material and clean formation of a single product. The solvent was removed in vacuo, the residual oil taken up in $\mathrm{CH}_{2} \mathrm{Cl}_{2}(60 \mathrm{~mL})$ and the resulting solution washed with a mixture of sat. $\mathrm{NaHCO}_{3}$ and $\mathrm{H}_{2} \mathrm{O}(1: 1,40 \mathrm{~mL})$, then brine $(40 \mathrm{~mL})$, dried $\left(\mathrm{MgSO}_{4}\right)$ and the solvent evaporated in vacuo to give the product 3 as a pale yellow oil $(4.56 \mathrm{~g}, 95 \%)$.

${ }^{1} \mathrm{H}$ NMR (300 MHz, $\mathrm{CDCl}_{3}$ ): $\delta$ ppm 4.51 - 4.37 (m, 1H,), 4.19 - 4.01 (m, 2H), 3.76 (s, 3H), $1.68-1.39(\mathrm{~m}, 15 \mathrm{H})$.

\section{(R)-2,2-Dimethyl-oxazolidine-3,4-dicarboxylic acid 3-tert-butyl ester (4)}

To a solution of (R)-2,2-Dimethyl-oxazolidine-3,4-dicarboxylic acid 3-tert-butyl ester 4methyl ester (3) (4.56 g, $17.59 \mathrm{mmol})$ in methanol (30 mL) was added $\mathrm{LiOH} 1 \mathrm{~N}(5 \mathrm{~mL})$ dropwise at $0{ }^{\circ} \mathrm{C}$ and stirred at room temperature until disappearance of starting material (TLC monitoring). The solvent was concentrated under reduced pressure and the resulting residue partitioned between ethyl ether and water. The organic phase was left aside and the aqueous phase was neutralized with $10 \%$ citric acid and extracted with ethyl acetate $(3 \times 100$ $\mathrm{mL})$, dried $\left(\mathrm{Na}_{2} \mathrm{SO}_{4}\right)$ and concentrated to give the acid $\mathbf{4}$ which was used for the next step without further purification $(3.71 \mathrm{~g}, 86 \%)$.

${ }^{1} \mathrm{H}$ NMR (300 MHz, $\left.\mathrm{CDCl}_{3}\right): \delta$ ppm 9.25 (bs, 1H), 4.55 - 4.38 (m, 1H), $4.25-4.10(\mathrm{~m}, 2 \mathrm{H})$, $1.68-1.40(\mathrm{~m}, 15 \mathrm{H})$.

(R)-4-(2-Benzoyl-phenylcarbamoyl)-2,2-dimethyl-oxazolidine-3-carboxylic acid tertbutyl ester (5)

To a solution of acid $4(3.71 \mathrm{~g}, 15.12 \mathrm{mmol})$ in $50 \mathrm{~mL}$ of dry $\mathrm{CH}_{2} \mathrm{Cl}_{2}$ at $0{ }^{\circ} \mathrm{C}$ was added $N$ methyl morpholine $(1.83 \mathrm{~mL}, 16.63 \mathrm{mmol})$ followed by isobutyl chloroformate $(2.16 \mathrm{~mL}$, $16.63 \mathrm{mmol})$. After $30 \mathrm{~min}$., a solution of 2-aminobenzophenone (2.98 g, $15.12 \mathrm{mmol})$ in $\mathrm{CH}_{2} \mathrm{Cl}_{2}$ was added to refluxing reaction mixture dropwise over $20 \mathrm{~min}$. After being stirred for $13 \mathrm{~h}$ at room temperature, the reaction mixture was washed with dilute $\mathrm{HCl}$, aqueous $\mathrm{NaHCO}_{3}$, and water. The organic layer was dried and concentrated to a residue and, after purification by column chromatography ( $25 \%$ ethyl acetate in hexane) gave the product (5) $(5.07 \mathrm{~g}, 79 \%)$.

$[\alpha]^{20}+115.3\left(c=1.08, \mathrm{CHCl}_{3}\right)$

${ }^{1} \mathrm{H}$ NMR (300 MHz, $\left.\mathrm{CDCl}_{3}\right): \delta 11.40-11.20(2 \mathrm{bs}, 1 \mathrm{H}), 8.69(\mathrm{~m}, 1 \mathrm{H}), 7.72-7.41(\mathrm{~m}, 7 \mathrm{H})$, $7.10(\mathrm{~m}, 1 \mathrm{H}), 4.59-4.38(\mathrm{~m}, 1 \mathrm{H}), 4.37-4.16(\mathrm{~m}, 2 \mathrm{H}), 1.87-1.20(\mathrm{~m}, 15 \mathrm{H}) ;{ }^{13} \mathrm{C}$ NMR $(75$ $\left.\mathrm{MHz}, \mathrm{CHCl}_{3}\right): \delta$ ppm 198.51, 133.88, 133.17, 132.35, 129.95, 128.16, 122.46, 121.41, 67.00, 
66.73, 28.18, 26.91, 25.96, 23.89, 22.98. Anal. Calcd. for $\mathrm{C}_{24} \mathrm{H}_{28} \mathrm{~N}_{2} \mathrm{O}_{5}: \mathrm{C}, 67.91 ; \mathrm{H}, 6.65 ; \mathrm{N}$, 6.60. Found: C, 67.74; H, 6.63; N, 6.59.

MS $\left(\mathrm{ESI}^{+}\right), \mathrm{m} / \mathrm{z} 870.9[2 \mathrm{M}+\mathrm{Na}]^{+}(100 \%), 447.1[\mathrm{M}+\mathrm{Na}]^{+}(55 \%), 425.0[\mathrm{M}+\mathrm{H}]^{+}(9 \%)$.

\section{(R)-3-Hydroxymethyl-5-phenyl-1,3-dihydro-benzo[e][1,4]diazepin-2-one (6)}

A solution of $5(5.07 \mathrm{~g}, 11.94 \mathrm{mmol})$ in methanol / $\mathrm{HCl} 5 \%(5 / 1,40 \mathrm{~mL})$ was refluxed for 7 $\mathrm{h}$ and then the solvent was concentrated under reduced pressure. The resulting residue was taken into the ethyl acetate and washed with aqueous $\mathrm{NaHCO}_{3}$, brine, dried and concentrated to afford crude product. Chromatography on silica gel (1\% methanol in ethyl acetate) gave 6 as a white solid $(2.70 \mathrm{~g}, 85 \%)$.

$[\alpha]_{\mathrm{D}}^{20}-107.5(c=1.02, \mathrm{MeOH})$

${ }^{1} \mathrm{H}$ NMR (300 MHz, $\left.\mathrm{CDCl}_{3}\right): \delta \mathrm{ppm} 8.65(\mathrm{bs}, 1 \mathrm{H}), 7.55$ - $7.13(\mathrm{~m}, 9 \mathrm{H}), 4.43(\mathrm{~m}, 1 \mathrm{H}), 4.26(\mathrm{~m}$, $1 \mathrm{H}), 3.82(\mathrm{t}, 1 \mathrm{H}, J=6.5 \mathrm{~Hz}), 2.88(\mathrm{~m}, 1 \mathrm{H}) ;{ }^{13} \mathrm{C} \mathrm{NMR}\left(75 \mathrm{MHz}, \mathrm{CD}_{3} \mathrm{OD}\right): \delta \mathrm{ppm} 172.38$, $172.07,140.27,140.26,133.19,132.23,131.62$, 131.27, 130.91, 129.26, 128.75, 124.45, 122.29, 65.98, 63.04. Anal. Calcd. for $\mathrm{C}_{16} \mathrm{H}_{14} \mathrm{~N}_{2} \mathrm{O}_{2} \cdot 0.2 \mathrm{H}_{2} \mathrm{O} \cdot 0.2 \mathrm{EtOAc}$ C, 70.18; H, 5.61; N, 9.74. Found: C, 70.20; H, 5.55; N, 9.91.

MS $\left(\mathrm{ESI}^{+}\right), \mathrm{m} / \mathrm{z} 555.0[2 \mathrm{M}+\mathrm{Na}]^{+}(100 \%), 289.2[\mathrm{M}+\mathrm{Na}]^{+}(13 \%), 267.2[\mathrm{M}+\mathrm{H}]^{+}(5 \%)$.

\section{(R)-3-(tert-Buthyl-dimethyl-silanyloxymethyl)-5-phenyl-1,3-dihydro-}

\section{benzo $[e][1,4]$ diazepin-2-one $(7)$}

To a solution of alcohol $6(2.70 \mathrm{~g}, 10.14 \mathrm{mmol})$ in $\mathrm{CH}_{2} \mathrm{Cl}_{2}(75 \mathrm{~mL})$ were added imidazole $(1.04 \mathrm{~g}, 15.21 \mathrm{mmol})$ and $\mathrm{TBS}-\mathrm{Cl}(1.89 \mathrm{~g}, 12.57 \mathrm{mmol})$ at $0{ }^{\circ} \mathrm{C}$. After stirring $12 \mathrm{~h}$ at room temperature the mixture washed with water and dried. Concentration under vacuum and column chromatography on silica gel (ethyl acetate/hexane 1/1) gave the $O$-protected derivative 7 (3.36 g, 87\%).

$[\alpha]^{20}{ }_{\mathrm{D}}-84.8\left(c=0.47, \mathrm{CHCl}_{3}\right)$

${ }^{1} \mathrm{H}$ NMR (300 MHz, $\left.\mathrm{CDCl}_{3}\right): \delta \mathrm{ppm} 9.60(\mathrm{bs}, 1 \mathrm{H}), 7.53-7.12(\mathrm{~m}, 9 \mathrm{H}), 4.62(\mathrm{dd}, 1 \mathrm{H}, J=10.0$

$\mathrm{Hz}$ and $6.3 \mathrm{~Hz}), 4.31(\mathrm{dd}, 1 \mathrm{H}, J=10.0 \mathrm{~Hz}$ and $6.3 \mathrm{~Hz}), 3.76(\mathrm{t}, 1 \mathrm{H}, J=6.3), 0.99(\mathrm{~s}, 9 \mathrm{H}), 0.19$ (s, 3H), 0.17 (s, 3H). ); $\left.{ }^{13} \mathrm{C} \mathrm{NMR} \mathrm{(75} \mathrm{MHz,} \mathrm{CHCl}_{3}\right): \delta \mathrm{ppm} 171.01,169.63,139.27,138.37$, 131.51, 131.10, 130.17, 129.77, 128.10, 127.66, 123.22, 121.32, 65.25, 63.76, 25.99, 18.52, 5.18. Anal. Calcd. for $\mathrm{C}_{22} \mathrm{H}_{28} \mathrm{~N}_{2} \mathrm{O}_{2} \mathrm{Si} \cdot 0.16 \mathrm{H}_{2} \mathrm{O} \cdot 0.16$ EtOAc: C, 68.36; H, 7.51; N, 7.03. Found: C, 68.66; H, 7.51; N, 7.20.

MS $\left(\mathrm{ESI}^{+}\right), \mathrm{m} / \mathrm{z} 783.0[2 \mathrm{M}+\mathrm{Na}]^{+}(100 \%), 403.2[\mathrm{M}+\mathrm{Na}]^{+}(4 \%), 381.3[\mathrm{M}+\mathrm{H}]^{+}(26 \%)$. 


\section{(R)-[3-(tert-Buthyl-dimethyl-silanyloxymethyl)-2-oxo-5-phenyl-2,3-dihydro-}

\section{benzo[e][1,4]diazepin-1-yl]-acetic acid ethyl ester (8)}

To a suspension of $\mathrm{NaH}(233 \mathrm{mg}, 9.71 \mathrm{mmol})$ in dry DMF (20 mL) was added a solution of 7 $(3.36 \mathrm{~g}, 8.83 \mathrm{mmol})$ in $\mathrm{DMF}(10 \mathrm{~mL})$ at $0{ }^{\circ} \mathrm{C}$ under nitrogen and then slowly reaction mixture brought into room temperature. After stirring $30 \mathrm{~min}$. at room temperature, ethyl bromoacetate $(1.2 \mathrm{~mL}, 11.04 \mathrm{mmol})$ was added via syringe and further stirred for $5 \mathrm{~h}$. The reaction mixture was quenched with sat. aqueous $\mathrm{NH}_{4} \mathrm{Cl}$ and extracted with ethyl acetate $(2 \mathrm{x}$ $100 \mathrm{~mL}$ ). The combined organic layers were washed with water, dried, concentrated and the resulting residue was purified on silica gel column chromatography (20\% ethyl acetate in hexane) to obtain the ester $8(3.21 \mathrm{~g}, 78 \%)$.

$[\alpha]^{20}-76.8\left(c=1.79, \mathrm{CHCl}_{3}\right)$

${ }^{1} \mathrm{H}$ NMR (300 MHz, $\left.\mathrm{CDCl}_{3}\right): \delta \mathrm{ppm} 7.65-7.18(\mathrm{~m}, 9 \mathrm{H}), 4.61-4.54(\mathrm{~m}, 3 \mathrm{H}), 4.33(\mathrm{dd}, 1 \mathrm{H}, J$ $=10.0$ and $6.3 \mathrm{~Hz}), 4.21-4.07(\mathrm{~m}, 2 \mathrm{H}), 3.85(\mathrm{t}, 1 \mathrm{H}, J=6.3 \mathrm{~Hz}), 1.17(\mathrm{t}, 3 \mathrm{H}, J=6.9 \mathrm{~Hz})$, 0.92 (s, 9H), 0.16 (s, 3H), 0.14 (s, 3H). ); ${ }^{13} \mathrm{C} \mathrm{NMR} \mathrm{(75} \mathrm{MHz,} \mathrm{CHCl}_{3}$ ): $\delta \mathrm{ppm} \mathrm{169.02,} \mathrm{168.90,}$ $168.55,142.32$, 138.72, 131.42, 130.29, 130.21, 129.88, 129.58, 128.08, 124.34, 121.48, 65.07, 63.95, 61.42, 49.53, 25.90, 18.40, 13.95, - 5.26. Anal. Calcd. for $\mathrm{C}_{26} \mathrm{H}_{34} \mathrm{~N}_{2} \mathrm{O}_{4} \mathrm{Si} \cdot 0.2 \mathrm{H}_{2} \mathrm{O}: \mathrm{C}, 66.41 ; \mathrm{H}, 7.37 ; \mathrm{N}, 5.96$. Found: C, 66.41; H, 7.76; N, 5.96.

MS $\left(\mathrm{ESI}^{+}\right), \mathrm{m} / \mathrm{z} 954.8[2 \mathrm{M}+\mathrm{Na}]^{+}(100 \%), 489.3[\mathrm{M}+\mathrm{Na}]^{+}(5 \%), 467.3[\mathrm{M}+\mathrm{H}]^{+}(56 \%)$.

\section{(R)-[3-(tert-Buthyl-dimethyl-silanyloxymethyl)-2-oxo-5-phenyl-2,3-dihydro-} benzo[ $e][1,4]$ diazepin-1-yl]-acetic acid (9)

To a solution of ester $8(3.21 \mathrm{~g}, 6.88 \mathrm{mmol})$ in methanol $(60 \mathrm{~mL})$ was added dropwise $1 \mathrm{~N}$ $\mathrm{LiOH}(15 \mathrm{~mL})$ keeping the temperature at $0{ }^{\circ} \mathrm{C}$ and stirred at room temperature until the disappearance of the starting material (TLC monitoring). The solvent was concentrated under reduced pressure and the resulting residue partitioned between ethyl ether and water. The organic phase was left aside and the aqueous phase was neutralized with $10 \%$ citric acid and extracted with ethyl acetate, dried $\left(\mathrm{Na}_{2} \mathrm{SO}_{4}\right)$ and concentrated to give the acid $9(2.47 \mathrm{~g}, 82 \%)$. $[\alpha]^{20}$ D $66.2(c=1.20, \mathrm{MeOH})$

${ }^{1} \mathrm{H}$ NMR (300 MHz, $\mathrm{CDCl}_{3}$ ): $\delta$ ppm $7.60-7.18$ (m, 9H), 6.60 (bs, 1H), $4.60-4.49$ (m, 3H), $4.31(\mathrm{dd}, 1 \mathrm{H}, J=6.3$ and $10.0 \mathrm{~Hz}), 3.83(\mathrm{t}, 1 \mathrm{H}, J=6.3 \mathrm{~Hz}), 0.90(\mathrm{~s}, 9 \mathrm{H}), 0.14(\mathrm{~s}, 3 \mathrm{H}), 0.12$ (s, $3 \mathrm{H}) ;{ }^{13} \mathrm{C}$ NMR (75 MHz, $\mathrm{CHCl}_{3}$ ): $\delta$ ppm 173.12, 169.56, 169.14, 142.08, 138.66, 131.66, $130.44,130.35,130.03,129.65,128.16,124.65,121.58,65.00,63.83,49.16,25.93,18.44$, 5.23. Anal. Calcd. for $\mathrm{C}_{24} \mathrm{H}_{30} \mathrm{~N}_{2} \mathrm{O}_{4} \mathrm{Si} \cdot 0.33 \mathrm{H}_{2} \mathrm{O}$ : C, 64.84; H, 6.95; N, 6.30. Found: C, 64.77; H, 7.24; N, 6.25. 
MS $\left(\mathrm{ESI}^{+}\right), \mathrm{m} / \mathrm{z} 899.1[2 \mathrm{M}+\mathrm{Na}]^{+}(12 \%), 439.3[\mathrm{M}+\mathrm{H}]^{+}(100 \%)$.

3(S)-(9H-Fluoren-9-ylmethoxycarbonylamino)- $N$-methoxy- $N$-methyl-succinamic acid tert-butyl ester (11)

Isobutyl chloroformate $(1.65 \mathrm{~mL}, 12.72 \mathrm{mmol})$ was added dropwise over $5 \mathrm{~min}$. period to a 0 ${ }^{\circ} \mathrm{C}$ cooled solution of Fmoc-beta-( $t$-butyl ester)-L-aspartic acid 10 (5 g, $\left.12.15 \mathrm{mmol}\right)$ and $\mathrm{N}$ methylmorpholine $(2.7 \mathrm{~mL}, 24.30 \mathrm{mmol})$ in dichlorometane $(100 \mathrm{~mL})$ under nitrogen atmosphere. After $30 \mathrm{~min}$. of stirring $N$, $O$-dimethylhydroxylamine $\cdot \mathrm{HCl}(1.18 \mathrm{~g}, 12.15 \mathrm{mmol})$ was added in one portion. The temperature was allowed to rise slowly to room temperature and stirred for $15 \mathrm{~h}$. The reaction mixture was diluted with ethyl acetate, washed with water, dried and concentrated to a residue. The obtained crude product was purified by column chromatography using 5\% methanol in $\mathrm{CH}_{2} \mathrm{Cl}_{2}$ to get pure amide 11 (4.75 g, 86\%).

${ }^{1} \mathrm{H}$ NMR (300 MHz, $\left.\mathrm{CDCl}_{3}\right): \delta \mathrm{ppm} 7.77$ - 7.28 (m, 8H), 5.89 (bs, 1H), 5.09 (m, 1H), $4.38(\mathrm{~d}$, $2 \mathrm{H}, J=6.6 \mathrm{~Hz}), 4.24(\mathrm{t}, 1 \mathrm{H}, J=6.6 \mathrm{~Hz}), 3.79(\mathrm{~s}, 3 \mathrm{H}), 3.24(\mathrm{~s}, 3 \mathrm{H}), 2.80-2.57(\mathrm{~m}, 2 \mathrm{H}), 1.47$ $(\mathrm{s}, 9 \mathrm{H})$.

\section{Fmoc-Asp(O-t-Bu)-semicarbazone (13)}

The Weinreb amide 11 (4.75 g, $10.45 \mathrm{mmol}$ ) was dissolved in anhydrous THF (70 mL) and LAH (475 mg, $12.52 \mathrm{mmol}$ ) was added slowly at $-65^{\circ} \mathrm{C}$, then raising the temperature naturally, and keep stirring for $2.5 \mathrm{~h}$. The reaction mixture was quenched by careful addition of $0.3 \mathrm{~N} \mathrm{KHSO}_{4}$ until both phases were clear to afford the crude aldehyde (12) after extractive work up with ethyl acetate which was used immediately without purification. The obtained crude aldehyde 12 was dissolved in aqueous ethanol (7/3 ethanol/water, $50 \mathrm{~mL}$ ) and sodium acetate $(857 \mathrm{mg}, 10.45 \mathrm{mmol})$ and semicarbazide hydrochloride $(1.17 \mathrm{~g}, 10.49 \mathrm{mmol})$ were then added at $0{ }^{\circ} \mathrm{C}$ and the reaction mixture was allowed to stir overnight. Excess ethanol was removed under reduced pressure. The resulting solution was diluted with water and extracted with ethyl acetate $(2 \times 100 \mathrm{~mL})$. The ethyl acetate layers were combined, washed, dried and concentrated to afford crude product. The residue was purified by silica gel chromatography using 5\% methanol in dichlorometane to provide semicarbazone 13 (2.60 g, 55\%).

${ }^{1} \mathrm{H}$ NMR (300 MHz, $\mathrm{CDCl}_{3}$ ): $\delta$ ppm 9.66 (bs, 1H), 7.77 - 7.28 (m, 8H), 7.13 (bs, 1H), 6.20 $5.08(2 \mathrm{bs}, 2 \mathrm{H}), 5.86(\mathrm{~d}, 1 \mathrm{H}, J=9.0 \mathrm{~Hz}), 4.75-4.65(\mathrm{~m}, 1 \mathrm{H}), 4.41(\mathrm{~d}, 2 \mathrm{H}, J=6.6 \mathrm{~Hz}), 4.21(\mathrm{t}$, $1 \mathrm{H}, J=6.6 \mathrm{~Hz}), 2.76-2.57(\mathrm{~m}, 2 \mathrm{H}), 1.43(\mathrm{~s}, 9 \mathrm{H})$. 


\section{3(R)-\{2-[((3S)-(tert-Buthyl-dimethyl-silanyloxymethyl)-2-oxo-5-phenyl-2,3-dihydro-}

benzo[e][1,4]diazepin-1-yl]-acetylamino\}-4-semicarbazone-butyric acid tert-butyl ester (14)

Semicarbazone 13 (2.60 g, $5.75 \mathrm{mmol})$ was dissolved in acetonitrile $(50 \mathrm{~mL})$, and diethylamine $(10 \mathrm{~mL})$ was added to the solution. The reaction mixture was stirred for $2 \mathrm{~h}$ at room temperature, concentrated in vacuo, the resulting residue was re-dissolved in acetonitrile and concentrated to dryness by rotatory evaporator to give free amine as a crude. A mixture of obtained crude amine and acid $9(2.47 \mathrm{~g}, 5.63 \mathrm{mmol})$ in $\mathrm{DMF} / \mathrm{CH}_{2} \mathrm{Cl}_{2}(1 / 1,40 \mathrm{~mL})$ was treated with EDCI $(1.34 \mathrm{~g}, 6.98 \mathrm{mmol})$ and HOBt hydrate $(761 \mathrm{mg}, 5.63 \mathrm{mmol})$ and the reaction mixture was stirred at room temperature for $15 \mathrm{~h}$, then diluted with ethyl acetate (100 $\mathrm{mL}$ ) and washed with water, aqueous $\mathrm{NaHCO}_{3}$, dried and concentrated under vacuum. Chromatography on silica gel $\left(\mathrm{MeOH} / \mathrm{CH}_{2} \mathrm{Cl}_{2}, 5 / 95\right)$ gave compound 14 (2.38 g, 65\%).

$[\alpha]^{20}{ }_{\mathrm{D}}-60.1\left(c=0.93, \mathrm{CHCl}_{3}\right)$

${ }^{1} \mathrm{H}$ NMR (300 MHz, $\left.\mathrm{CDCl}_{3}\right): \delta \mathrm{ppm} 9.56(\mathrm{bs}, 1 \mathrm{H}), 7.67-7.15(\mathrm{~m}, 11 \mathrm{H}), 6.07-5.54(\mathrm{bs}, 2 \mathrm{H})$, $4.93-4.84(\mathrm{~m}, 1 \mathrm{H}), 4.58(\mathrm{ABd}, 1 \mathrm{H}, J=15.6 \mathrm{~Hz}), 4.45-4.40(\mathrm{~m}, 1 \mathrm{H}), 4.36-4.30(\mathrm{~m}, 1 \mathrm{H})$, $4.25(\mathrm{ABd}, 1 \mathrm{H}, J=15.6 \mathrm{~Hz}), 3.80(\mathrm{t}, 1 \mathrm{H}, J=6.0 \mathrm{~Hz}), 2.63-2.38(\mathrm{~m}, 2 \mathrm{H}), 1.37(\mathrm{~s}, 9 \mathrm{H}), 0.87$ $(\mathrm{s}, 9 \mathrm{H}), 0.12(\mathrm{~s}, 3 \mathrm{H}), 0.08(\mathrm{~s}, 3 \mathrm{H}) ;{ }^{13} \mathrm{C} \mathrm{NMR}\left(75 \mathrm{MHz}, \mathrm{CHCl}_{3}\right): \delta \mathrm{ppm} \mathrm{169.88,} \mathrm{169.70,}$ $169.31,167.87,157.65,142.49,140.74,138.41,131.79,130.50,130.07,129.65,129.47$, $128.19,124.79,122.70,81.36,65.13,63.87,52.44,47.27,37.77,27.96,22.88,18.37,-5.19$. Anal. Calcd. for $\mathrm{C}_{33} \mathrm{H}_{46} \mathrm{~N}_{6} \mathrm{O}_{6} \mathrm{Si} \cdot 0.33 \mathrm{H}_{2} \mathrm{O} \cdot 0.33 \mathrm{MeOH}$ : C, 59.98; H, 7.25; N, 12.59. Found: C, 59.99; H, 7.31; N, 12.59.

MS $\left(\mathrm{ESI}^{+}\right), \mathrm{m} / \mathrm{z} 673.3[\mathrm{M}+\mathrm{Na}]^{+}(100 \%), 651.3[\mathrm{M}+\mathrm{H}]^{+}(28 \%)$.

\section{3(R)-[2-((3S)-Hydroxymethyl-2-oxo-5-phenyl-2,3-dihydro-benzo[e][1,4]diazepin-1-yl)-} acetylamino]-4-semicarbazone-butyric acid tert-butyl ester

To a solution of 14 (2.38 g, $3.66 \mathrm{mmol})$ in dry THF (25 mL) was added tetrabutylammonium fluoride (1 $\mathrm{M}$ in THF, $5 \mathrm{~mL}$ ) and stirred for $5 \mathrm{~h}$ at room temperature. The reaction mixture was diluted with ethyl acetate and washed with water. The organic layer was dried and concentrated to give a residue which was passed through silica gel using $10 \%$ methanol in $\mathrm{CH}_{2} \mathrm{Cl}_{2}$ to give the desired hydroxymethyl derivative $(1.65 \mathrm{~g}, 84 \%)$.

$[\alpha]^{20}{ }_{\mathrm{D}}-53.8\left(c=0.50, \mathrm{CHCl}_{3}\right)$

${ }^{1} \mathrm{H}$ NMR (300 MHz, $\left.\mathrm{CDCl}_{3}\right): \delta$ ppm $9.63(\mathrm{bs}, 1 \mathrm{H}), 8.30$ (d, 1H, $\left.J=8.4 \mathrm{~Hz}\right), 7.91(\mathrm{~d}, 1 \mathrm{H}, J=$ $8.1 \mathrm{~Hz}), 7.63-7.54(\mathrm{~m}, 3 \mathrm{H}), 7.47-7.19(\mathrm{~m}, 6 \mathrm{H}), 6.10(\mathrm{bs}, 2 \mathrm{H}), 5.09-4.99(\mathrm{~m}, 1 \mathrm{H}), 4.61$ (d, 
$1 \mathrm{H}, J=15.6 \mathrm{~Hz}), 4.53-4.43(\mathrm{~m}, 1 \mathrm{H}), 4.14(\mathrm{~d}, 1 \mathrm{H}, J=15.6 \mathrm{~Hz}), 4.13-4.05(\mathrm{~m}, 1 \mathrm{H}), 3.79(\mathrm{t}$, $1 \mathrm{H}, J=6.6 \mathrm{~Hz}), 3.50$ (bs, 1H), $2.75-2.54(\mathrm{~m}, 2 \mathrm{H}), 1.47(\mathrm{~s}, 9 \mathrm{H}) ;{ }^{13} \mathrm{C} \mathrm{NMR}\left(75 \mathrm{MHz}, \mathrm{CHCl}_{3}\right)$ : $\delta$ ppm 170.61, 170.03, 169.58, 169.02, 157.97, 142.68, 141.96, 138.32, 138.24, 131.95, 130.50, 129.86, 129.63, 129.06, 128.15, 124.77, 122.95, 81.15, 64.05, 62.36, 53.33, 47.40, 36.71, 27.91. Anal. Calcd. for $\mathrm{C}_{27} \mathrm{H}_{32} \mathrm{~N}_{6} \mathrm{O}_{6} \cdot 1.0 \mathrm{H}_{2} \mathrm{O} \cdot 0.5 \mathrm{MeOH}$ : C, 57.88; H, 6.36; N, 14.73 . Found: C, 57.96; H, 6.21; N, 14.65.

MS (ESI $\left.{ }^{+}\right), \mathrm{m} / \mathrm{z} 559.1[\mathrm{M}+\mathrm{Na}]^{+}(58 \%), 537.1[\mathrm{M}+\mathrm{H}]^{+}(18 \%), 242.4(100 \%), 186.3(45 \%)$.

\section{4-Semicarbazone-3(S)-[2-(2-oxo-5-phenyl-3(R)-(phenylcarbamoyloxymethyl)-2,3-} dihydro-benzo[ $e][1,4]$ diazepin-1-yl)-acetylamino]-butyric acid tert-butyl ester (15a)

A stirred solution of alcohol $(200 \mathrm{mg}, 0.37 \mathrm{mmol})$ in dry $\mathrm{CH}_{2} \mathrm{Cl}_{2}(5 \mathrm{~mL})$ was treated with phenyl isocyanate $(90 \mu \mathrm{l}, 0.74 \mathrm{mmol})$ for $12 \mathrm{~h}$ under nitrogen atmosphere at room temperature. The reaction mixture was diluted with ethyl acetate $(20 \mathrm{~mL})$ and washed with water. The ethyl acetate layer was dried and concentrated to a residue. Silica gel column chromatography (5\% methanol in $\mathrm{CH}_{2} \mathrm{Cl}_{2}$ ) gave carbamate 15a (191 mg, 78\%).

$[\alpha]^{20}{ }_{\mathrm{D}}-72.7\left(c=0.30, \mathrm{CHCl}_{3}\right)$

${ }^{1} \mathrm{H}$ NMR (300 MHz, $\left.\mathrm{CDCl}_{3}\right): \delta$ ppm $9.65(\mathrm{bs}, 1 \mathrm{H}), 8.02-7.92(\mathrm{~m}, 2 \mathrm{H}), 7.68(\mathrm{~d}, 1 \mathrm{H}, J=8.1$ $\mathrm{Hz}), 7.58(\mathrm{~d}, 2 \mathrm{H}, J=8.4 \mathrm{~Hz}), 7.52-7.24(\mathrm{~m}, 9 \mathrm{H}), 7.17(\mathrm{t}, 1 \mathrm{H}, J=8.1 \mathrm{~Hz}), 7.08(\mathrm{t}, 1 \mathrm{H}, J=8.1$ Hz), 6.90 (t, 1H, J= $7.5 \mathrm{~Hz}), 6.30$ (bs, 1H), 5.69 (bs, 1H), $5.06-4.94$ (m, 1H), 4.89 (d, 2H, $J$ $=6.6 \mathrm{~Hz}), 4.67(\mathrm{ABd}, 1 \mathrm{H}, J=15.9 \mathrm{~Hz}), 4.20(\mathrm{ABd}, 1 \mathrm{H}, J=15.9 \mathrm{~Hz}), 4.03(\mathrm{t}, 1 \mathrm{H}, J=6.6$ $\mathrm{Hz}), 2.75-2.50(\mathrm{~m}, 2 \mathrm{H}), 1.37(\mathrm{~s}, 6 \mathrm{H}), 1.27(\mathrm{~s}, 3 \mathrm{H}) ;{ }^{13} \mathrm{C} \mathrm{NMR}\left(75 \mathrm{MHz}, \mathrm{CHCl}_{3}\right): \delta \mathrm{ppm}$ $169.98,169.77,169.53,168.18,157.45,153.55,142.37,141.28,138.15,138.04,132.21$, $130.78,130.24,129.79,129.02$, 128.88, 128.77, 128.30, 125.05, 123.05, 118.78, 81.50, 64.17, 62.00, 53.35, 47.26, 37.57, 29.25, 28.03, 27.89. Anal. Calcd. for $\mathrm{C}_{34} \mathrm{H}_{37} \mathrm{~N}_{7} \mathrm{O}_{7}: \mathrm{C}, 62.28 ; \mathrm{H}$, 5.69; N, 14.95. Found: C, 62.34; H, 5.67; N, 14.91.

MS $\left(\mathrm{ESI}^{+}\right), \mathrm{m} / \mathrm{z} 1334.0[2 \mathrm{M}+\mathrm{Na}]^{+}(38 \%), 1332.9(48 \%), 678.3[\mathrm{M}+\mathrm{Na}]^{+}(100 \%), 656.2[\mathrm{M}$ $+\mathrm{H}]^{+}(70 \%)$.

HRMS Calcd. for $\mathrm{C}_{34} \mathrm{H}_{38} \mathrm{~N}_{7} \mathrm{O}_{7}[\mathrm{M}+\mathrm{H}]^{+}$: 656.2833. Found: $656.2844[\mathrm{M}+\mathrm{H}]^{+}$.

\section{4-Semicarbazone-3(S)-[2-(2-oxo-5-phenyl-3(R)-(1-naphthylcarbamoyloxymethyl)-2,3-} dihydro-benzo[ $e][1,4]$ diazepin-1-yl)-acetylamino]-butyric acid tert-butyl ester (15b)

With a similar procedure alcohol $(200 \mathrm{mg}, 0.37 \mathrm{mmol})$ and 1-naphthyl isocyanate $(106 \mu \mathrm{l}$, $0.74 \mathrm{mmol}$ ) gave carbamate $\mathbf{1 5 b}(189 \mathrm{mg}, 72 \%)$.

$[\alpha]^{20}{ }_{\mathrm{D}}-79.3\left(c=0.35, \mathrm{CHCl}_{3}\right)$ 
${ }^{1} \mathrm{H}$ NMR (300 MHz, $\mathrm{CDCl}_{3}$ ): $\delta 9.40$ (bs, 1H), $8.22-7.26$ (m, 16H), 7.13 (dd, 2H, $J=7.5 \mathrm{~Hz}$ and $J=1.5 \mathrm{~Hz}), 6.96(\mathrm{t}, 1 \mathrm{H}, J=7.8 \mathrm{~Hz}), 6.37(\mathrm{bs}, 2 \mathrm{H}), 5.09-4.94(\mathrm{~m}, 3 \mathrm{H}), 4.60(\mathrm{ABd}, 1 \mathrm{H}, J$ $=15.6 \mathrm{~Hz}), 4.14-4.02(\mathrm{~m}, 1 \mathrm{H}), 4.11(\mathrm{ABd}, 1 \mathrm{H}, J=15.6 \mathrm{~Hz}), 2.70-2.57(\mathrm{~m}, 2 \mathrm{H}), 1.41(\mathrm{~s}$, $6 \mathrm{H}), 1.29$ (s, 3H); ${ }^{13} \mathrm{C}$ NMR (75 MHz, $\left.\mathrm{CHCl}_{3}\right): \delta$ ppm 170.01, 169.89, 169.56, 168.21, $157.42,153.70,142.58,141.30,138.13,135.54,134.47,132.15,132.08,132.00,130.76$, $130.38,129.92$, 129.71, 129.65, 128.35, 128.31, 126.94, 126.80, 125.49, 124.96, 122.51, $122.22,81.50,64.24,61.99,53.46,47.25,37.54,29.26,28.06,27.88$. Anal. Calcd. for $\mathrm{C}_{38} \mathrm{H}_{39} \mathrm{~N}_{7} \mathrm{O}_{7}: \mathrm{C}, 64.67 ; \mathrm{H}, 5.57 ; \mathrm{N}, 13.89$. Found: C, 64.66; H, 5.52; N, 13.87.

MS $\left(\mathrm{ESI}^{+}\right), \mathrm{m} / \mathrm{z} 1433.6[2 \mathrm{M}+\mathrm{Na}]^{+}(43 \%), 728.3[\mathrm{M}+\mathrm{Na}]^{+}(100 \%), 706.3[\mathrm{M}+\mathrm{H}]^{+}(55 \%)$.

HRMS Calcd. for $\mathrm{C}_{38} \mathrm{H}_{40} \mathrm{~N}_{7} \mathrm{O}_{7}[\mathrm{M}+\mathrm{H}]^{+}:$706.2989. Found: 706.2994 [M+H] .

\section{4-Semicarbazone-3(S)-[2-(2-oxo-5-phenyl-3(R)-(4-methoxyphenylcarbamoyloxymethyl)-} 2,3-dihydro-benzo[ $e][1,4]$ diazepin-1-yl)-acetylamino]-butyric acid tert-butyl ester (15c)

With a similar procedure alcohol $(200 \mathrm{mg}, 0.37 \mathrm{mmol})$ and 4-methoxyphenyl isocyanate (96 $\mu 1,0.74 \mathrm{mmol})$ gave carbamate $15 \mathrm{c}(189 \mathrm{mg}, 74 \%)$.

$[\alpha]^{20}-27.7\left(c=0.42, \mathrm{CHCl}_{3}\right)$

${ }^{1} \mathrm{H}$ NMR $\left(300 \mathrm{MHz}, \mathrm{CDCl}_{3}\right): \delta 9.70(\mathrm{bs}, 1 \mathrm{H}), 8.20-7.18(\mathrm{~m}, 13 \mathrm{H}), 6.76(\mathrm{~d}, 1 \mathrm{H}, J=8.7 \mathrm{~Hz})$, $6.68(\mathrm{~d}, 2 \mathrm{H}, J=8.6 \mathrm{~Hz}), 6.32(\mathrm{bs}, 1 \mathrm{H}), 5.65$ (bs, 1H), $5.08-4.82(\mathrm{~m}, 3 \mathrm{H}), 4.67(\mathrm{ABd}, 1 \mathrm{H}, J=$ $15.8 \mathrm{~Hz}), 4.22(\mathrm{ABd}, 1 \mathrm{H}, J=15.8 \mathrm{~Hz}), 4.03(\mathrm{t}, 1 \mathrm{H}, J=6.4 \mathrm{~Hz}), 3.70(\mathrm{~s}, 3 \mathrm{H}), 2.80-2.57$ (m, 2H), 1.39 (s, 6H), 1.27 (s, 3H); ${ }^{13} \mathrm{C}$ NMR (75 MHz, $\mathrm{CHCl}_{3}$ ): $\delta \mathrm{ppm} 169.99,169.82,169.38$, 168.49 , 157.64, 157.36, 153.51, 142.38, 141.40, 138.11, 132.15, 130.78, 130.45, 130.26, $129.78,128.97,128.26,125.04,123.91,118.84,114.27,81.45,64.16,61.97,55.78,53.23$, 47.24, 37.61, 29.20, 28.01, 27.98. Anal. Calcd. for $\mathrm{C}_{35} \mathrm{H}_{39} \mathrm{~N}_{7} \mathrm{O}_{8}: \mathrm{C}, 61.30 ; \mathrm{H}, 5.73 ; \mathrm{N}, 14.30$. Found: C, 61.28; H, 5.67; N, 14.32.

MS $\left(\mathrm{ESI}^{+}\right), \mathrm{m} / \mathrm{z} 724.2[\mathrm{M}+\mathrm{K}]^{+}(16 \%), 708.3[\mathrm{M}+\mathrm{Na}]^{+}(76 \%), 686.3[\mathrm{M}+\mathrm{H}]^{+}(100 \%)$. HRMS Calcd. for $\mathrm{C}_{35} \mathrm{H}_{40} \mathrm{~N}_{7} \mathrm{O}_{8}[\mathrm{M}+\mathrm{H}]^{+}$: 686.2938. Found: $686.2925[\mathrm{M}+\mathrm{H}]^{+}$.

\section{4-Semicarbazone-3(S)-[2-(2-oxo-5-phenyl-3(R)-(4-chlorophenylcarbamoyloxymethyl)-}

\section{2,3-dihydro-benzo[e][1,4]diazepin-1-yl)-acetylamino]-butyric acid tert-butyl ester (15d)}

With a similar procedure alcohol $(200 \mathrm{mg}, 0.37 \mathrm{mmol})$ and 4-chlorophenyl isocyanate $(95 \mu \mathrm{l}$, $0.74 \mathrm{mmol}$ ) gave carbamate $\mathbf{1 5 d}(193 \mathrm{mg}, 75 \%)$.

$[\alpha]^{20}{ }_{\mathrm{D}}-30.2\left(c=0.15, \mathrm{CHCl}_{3}\right)$

${ }^{1} \mathrm{H}$ NMR $\left(300 \mathrm{MHz}, \mathrm{CDCl}_{3}\right): \delta 9.82-9.61(\mathrm{~m}, 1 \mathrm{H}), 8.22-7.12(\mathrm{~m}, 14 \mathrm{H}), 7.02(\mathrm{~d}, 2 \mathrm{H}, J=$ $8.5 \mathrm{~Hz}), 6.34$ (bs, 1H), 5.50 (bs, 1H), $5.10-4.78$ (m, 3H), 4.71 (ABd, 1H, J = $15.6 \mathrm{~Hz}), 4.20$ 
$(\mathrm{ABd}, 1 \mathrm{H}, J=15.6 \mathrm{~Hz}), 4.04(\mathrm{t}, 1 \mathrm{H}, J=6.7 \mathrm{~Hz}), 2.80-2.55(\mathrm{~m}, 2 \mathrm{H}), 1.41(\mathrm{~s}, 6 \mathrm{H}), 1.28$ (s, $3 \mathrm{H}) ;{ }^{13} \mathrm{C}$ NMR $\left(75 \mathrm{MHz}, \mathrm{CHCl}_{3}\right): \delta$ ppm 169.93, 169.83, 169.48, 168.25, 157.41, 153.44, $142.31,141.32,138.07,136.68,132.25,130.86,130.30,129.78,128.97,128.82,128.71$, 128.33, 125.10, 122.97, 119.96, 81.60, 64.22, 61.94, 53.44, 47.24, 37.47, 28.04, 27.87. Anal. Calcd. for $\mathrm{C}_{34} \mathrm{H}_{36} \mathrm{ClN}_{7} \mathrm{O}_{7}$ : C, 59.17; H, 5.26; N, 14.21. Found: C, 59.24; H, 5.26; N, 14.18. MS $\left(\mathrm{ESI}^{+}\right), \mathrm{m} / \mathrm{z} 1402.9[2 \mathrm{M}+\mathrm{Na}]^{+}(17 \%), 1400.8(19 \%), 712.2[\mathrm{M}+\mathrm{Na}]^{+}(100 \%), 690.1[\mathrm{M}$ $+\mathrm{H}]^{+}(10 \%)$.

HRMS Calcd. for $\mathrm{C}_{34} \mathrm{H}_{36} \mathrm{~N}_{7} \mathrm{O}_{7} \mathrm{ClNa}[\mathrm{M}+\mathrm{Na}]^{+}:$712.2262. Found: $712.2293[\mathrm{M}+\mathrm{Na}]^{+}$.

\section{4-Semicarbazone-3(S)-[2-(2-oxo-5-phenyl-3(R)-(4-fluorophenylcarbamoyloxymethyl)-}

\section{2,3-dihydro-benzo[e][1,4]diazepin-1-yl)-acetylamino]-butyric acid tert-butyl ester (15e)}

With a similar procedure alcohol $(200 \mathrm{mg}, 0.37 \mathrm{mmol})$ and 4-fluorophenyl isocyanate $(83 \mu \mathrm{l}$, $0.74 \mathrm{mmol})$ gave carbamate $\mathbf{1 5 e}(197 \mathrm{mg}, 79 \%)$.

$[\alpha]^{20} \mathrm{D}-32.8\left(c=0.34, \mathrm{CHCl}_{3}\right)$

${ }^{1} \mathrm{H}$ NMR $\left(300 \mathrm{MHz}, \mathrm{CDCl}_{3}\right): \delta 9.80$ (bs, 1H), $8.43-7.89(\mathrm{~m}, 2 \mathrm{H}), 7.82-7.19(\mathrm{~m}, 11 \mathrm{H}), 6.87$ $(\mathrm{t}, 1 \mathrm{H}, J=8.3 \mathrm{~Hz}), 6.71(\mathrm{t}, 2 \mathrm{H}, J=7.7 \mathrm{~Hz}), 6.21(\mathrm{bs}, 1 \mathrm{H}), 5.78(\mathrm{bs}, 1 \mathrm{H}), 5.12-4.78(\mathrm{~m}, 3 \mathrm{H})$, $4.70(\mathrm{ABd}, 1 \mathrm{H}, J=15.8 \mathrm{~Hz}), 4.22(\mathrm{ABd}, 1 \mathrm{H}, J=15.8 \mathrm{~Hz}), 4.03(\mathrm{t}, 1 \mathrm{H}, J=6.5 \mathrm{~Hz}), 2.80-$ $2.55(\mathrm{~m}, 2 \mathrm{H}), 1.37(\mathrm{~s}, 6 \mathrm{H}), 1.28(\mathrm{~s}, 3 \mathrm{H}) ;{ }^{13} \mathrm{C} \mathrm{NMR}\left(75 \mathrm{MHz}, \mathrm{CHCl}_{3}\right): \delta \mathrm{ppm} 170.15,169.86$, 169.36, 168.52, 159.92, 157.96, 157.25, 153.73, 142.42, 141.68, 138.14, 134.18, 132.13, $130.79,130.57,130.28,129.78,128.98,128.28,124.70,122.84,119.87,115.39,115.14$, 81.50, 63.94, 61.91, 53.06, 47.35, 37.66, 28.00, 27.86. Anal. Calcd. for $\mathrm{C}_{34} \mathrm{H}_{36} \mathrm{FN}_{7} \mathrm{O}_{7}$ : $\mathrm{C}$, 60.62; H, 5.39; N, 14.55. Found: C, 60.60; H, 5.33; N, 14.56.

MS $\left(\mathrm{ESI}^{+}\right), \mathrm{m} / \mathrm{z} 1368.6[2 \mathrm{M}+\mathrm{Na}]^{+}(13 \%), 1346.6[2 \mathrm{M}+\mathrm{H}]^{+}(24 \%), 696.1[\mathrm{M}+\mathrm{Na}]^{+}(29 \%)$, $674.2[\mathrm{M}+\mathrm{H}]^{+}(100 \%)$,

HRMS Calcd. for $\mathrm{C}_{34} \mathrm{H}_{36} \mathrm{~N}_{7} \mathrm{O}_{7} \mathrm{FNa}[\mathrm{M}+\mathrm{Na}]^{+}$: 696.2558. Found: $696.2554[\mathrm{M}+\mathrm{Na}]^{+}$.

\section{4-Semicarbazone-3(S)-[2-(2-oxo-5-phenyl-3(R)-(2,4-}

difluorophenylcarbamoyloxymethyl)-2,3-dihydro-benzo[ $e][1,4]$ diazepin-1-yl)acetylamino]-butyric acid tert-butyl ester (15f)

With a similar procedure alcohol (200 $\mathrm{mg}, 0.37 \mathrm{mmol})$ and 2,4-difluorophenyl isocyanate (88 $\mu \mathrm{l}, 0.74 \mathrm{mmol})$ gave carbamate $\mathbf{1 5 f}(196 \mathrm{mg}, 76 \%)$.

$[\alpha]^{20}{ }_{\mathrm{D}}-46.9\left(c=0.45, \mathrm{CHCl}_{3}\right)$

${ }^{1} \mathrm{H}$ NMR $\left(300 \mathrm{MHz}, \mathrm{CDCl}_{3}\right.$ ): $\delta 9.70$ (bs, 1H), 7.98 (bs, 1H), $7.85-7.17(\mathrm{~m}, 11 \mathrm{H}), 7.15(\mathrm{t}, 1 \mathrm{H}$, $J=7.3 \mathrm{~Hz}$ ), $6.86-6.62$ (m, 2H), 6.29 (bs, 1H), 5.52 (bs, 1H), $5.11-4.78$ (m, 3H), 4.66 
$(\mathrm{ABd}, 1 \mathrm{H}, J=14.7 \mathrm{~Hz}), 4.20(\mathrm{ABd}, 1 \mathrm{H}, J=14.7 \mathrm{~Hz}), 4.07(\mathrm{t}, 1 \mathrm{H}, J=6.3 \mathrm{~Hz}), 2.96-2.34(\mathrm{~m}$, 2H), $1.40(\mathrm{~s}, 6 \mathrm{H}), 1.27(\mathrm{~s}, 3 \mathrm{H}) ;{ }^{13} \mathrm{C} \mathrm{NMR}\left(75 \mathrm{MHz}, \mathrm{CHCl}_{3}\right): \delta \mathrm{ppm} 170.00,169.76,169.41$, $168.14,159.60,159.48,157.99,156.89,156.77,154.26,154.13,153.67,151.53,151.40$, $142.39,141.58,138.08,131.93$, 130.66, 129.99, 129.70, 128.92, 128.18, 124.76, 122.80, 122.49, 122.40, 111.00, 110.77, 103.68, 103.39, 103.13, 81.27, 64.76, 61.80, 52.99, 47.34, 37.44, 27.91. Anal. Calcd. for $\mathrm{C}_{34} \mathrm{H}_{35} \mathrm{~F}_{2} \mathrm{~N}_{7} \mathrm{O}_{7}$ : C, 59.04; H, 5.10; N, 14.18. Found: C, 59.00; $\mathrm{H}, 5.13 ; \mathrm{N}, 14.21$.

MS $\left(\mathrm{ESI}^{+}\right), \mathrm{m} / \mathrm{z} 714.2[\mathrm{M}+\mathrm{Na}]^{+}(100 \%), 692.3[\mathrm{M}+\mathrm{H}]^{+}(50 \%)$.

HRMS Calcd. for $\mathrm{C}_{34} \mathrm{H}_{36} \mathrm{~N}_{7} \mathrm{O}_{7} \mathrm{~F}_{2}[\mathrm{M}+\mathrm{H}]^{+}$: 692.2644. Found: $692.2639[\mathrm{M}+\mathrm{H}]^{+}$.

\section{4-Semicarbazone-3(S)-[2-(2-oxo-5-phenyl-3(R)-(2-bromo-4,6-}

\section{difluorophenylcarbamoyloxymethyl)-2,3-dihydro-benzo[e][1,4]diazepin-1-yl)-} acetylamino]-butyric acid tert-butyl ester (15g)

With a similar procedure alcohol $(200 \mathrm{mg}, 0.37 \mathrm{mmol})$ and 2-bromo-4,6-difluorophenyl isocyanate (99 $\mu \mathrm{l}, 0.74 \mathrm{mmol})$ gave carbamate $15 \mathrm{~g}(228 \mathrm{mg}, 80 \%)$.

$[\alpha]^{20}{ }_{\mathrm{D}}-56.3\left(c=0.19, \mathrm{CHCl}_{3}\right)$

${ }^{1} \mathrm{H}$ NMR (300 MHz, $\left.\mathrm{CDCl}_{3}\right): \delta 9.88$ (bs, 1H), $8.25-8.08$ (m, 1H), 8.02 (bs, 1H), $7.71-7.08$ (m, 9H), $7.02(\mathrm{~d}, 1 \mathrm{H}, J=7.6 \mathrm{~Hz}), 6.88-6.74(\mathrm{~m}, 1 \mathrm{H}), 6.64-6.53(\mathrm{~m}, 1 \mathrm{H}), 6.23$ (bs, 1H), 5.36 (bs, 1H), $5.11-4.78(\mathrm{~m}, 3 \mathrm{H}), 4.63(\mathrm{ABd}, 1 \mathrm{H}, J=15.8 \mathrm{~Hz}), 4.21-4.08(\mathrm{~m}, 1 \mathrm{H}), 4.10$ $(\mathrm{ABd}, 1 \mathrm{H}, J=15.8 \mathrm{~Hz}), 2.80-2.57(\mathrm{~m}, 2 \mathrm{H}), 1.42(\mathrm{~s}, 6 \mathrm{H}), 1.27(\mathrm{~s}, 3 \mathrm{H}) ;{ }^{13} \mathrm{C}$ NMR $(75 \mathrm{MHz}$, $\left.\mathrm{CHCl}_{3}\right): \delta$ ppm 169.98, 169.65, 169.20, 168.34, 161.98, 161.84, 160.09, 159.94, 159.20, $159.06,157.91,157.28,157.13,154.55,142.34$, 141.57, 138.14, 131.66, 130.69, 129.93, $129.71,128.90,128.21,124.77,124.17,124.05,122.91,121.77,121.73,121.60,121.56$, 115.64, 115.61, 115.37, 115.33, 104.03, 103.75, 103.47, 81.32, 64.87, 61.55, 53.41, 47.26, 37.05, 27.98, 27.91. Anal. Calcd. for $\mathrm{C}_{34} \mathrm{H}_{34} \mathrm{BrF}_{2} \mathrm{~N}_{7} \mathrm{O}_{7}$ : C, 52.99; H, 4.45; N, 12.72. Found: $\mathrm{C}$, $53.02 ; \mathrm{H}, 4.44 ; \mathrm{N}, 12.76$.

MS $\left(\mathrm{ESI}^{+}\right), \mathrm{m} / \mathrm{z} 810.2\left[\mathrm{M}\left({ }^{81} \mathrm{Br}\right)+\mathrm{K}\right]^{+}(24 \%), 808.1\left[\mathrm{M}\left({ }^{79} \mathrm{Br}\right)+\mathrm{K}\right]^{+}(17 \%), 794.2\left[\mathrm{M}\left({ }^{81} \mathrm{Br}\right)+\right.$ $\mathrm{Na}]^{+}(100 \%), 792.2\left[\mathrm{M}\left({ }^{79} \mathrm{Br}\right)+\mathrm{Na}\right]^{+}(95 \%), 772.2\left[\mathrm{M}\left({ }^{81} \mathrm{Br}\right)+\mathrm{H}\right]^{+}(92 \%), 770.2\left[\mathrm{M}\left({ }^{79} \mathrm{Br}\right)+\right.$ $\mathrm{H}]^{+}(91 \%)$.

HRMS Calcd. for $\mathrm{C}_{34} \mathrm{H}_{35} \mathrm{~N}_{7} \mathrm{O}_{7} \mathrm{~F}_{2} \mathrm{Br}\left[\mathrm{M}\left({ }^{79} \mathrm{Br}\right)+\mathrm{H}\right]^{+}$: 770.1749 . Found: $770.1719\left[\mathrm{M}\left({ }^{79} \mathrm{Br}\right)+\right.$ $\mathrm{H}]^{+}$. 


\section{4-Semicarbazone-3(S)-[2-(2-oxo-5-phenyl-3(R)-(4-chloro-2-}

\section{methylphenylcarbamoyloxymethyl)-2,3-dihydro-benzo[e][1,4]diazepin-1-yl)-}

acetylamino]-butyric acid tert-butyl ester (15h)

With a similar procedure alcohol $(200 \mathrm{mg}, 0.37 \mathrm{mmol})$ and 4-chloro-2-methylphenyl isocyanate (124 mg, $0.74 \mathrm{mmol})$ gave carbamate $\mathbf{1 5 h}(172 \mathrm{mg}, 66 \%)$.

$[\alpha]^{20}{ }_{\mathrm{D}}-41.3\left(c=0.16, \mathrm{CHCl}_{3}\right)$

${ }^{1} \mathrm{H}$ NMR (300 MHz, $\mathrm{CDCl}_{3}$ ): $\delta 9.62$ (bs, 1H), 7.97 (bs, 1H), 7.77 - 6.94 (m, 14H), 6.32 (bs, 1H), 5.37 (bs, 1H), $5.11-4.79(\mathrm{~m}, 3 \mathrm{H}), 4.65(\mathrm{ABd}, 1 \mathrm{H}, J=14.8 \mathrm{~Hz}), 4.20(\mathrm{ABd}, 1 \mathrm{H}, J=$ $14.8 \mathrm{~Hz}), 4.13-3.95(\mathrm{~m}, 1 \mathrm{H}), 2.78-2.49(\mathrm{~m}, 2 \mathrm{H}), 2.15(\mathrm{~s}, 3 \mathrm{H}), 1.41(\mathrm{~s}, 6 \mathrm{H}), 1.27(\mathrm{~s}, 3 \mathrm{H}) ;{ }^{13} \mathrm{C}$ NMR (75 MHz, $\left.\mathrm{CHCl}_{3}\right): \delta$ ppm 170.03, 169.76, 169.53, 168.20, 157.92, 154.10, 142.38, $141.55,138.09,134.52$, 132.03, 130.73, 129.99, 129.73, 129.22, 128.91, 128.06, 126.41, $124.88,122.81,81.38,64.51,61.93,53.09,47.34,37.47,27.96,27.86,17.61$. Anal. Calcd. for $\mathrm{C}_{35} \mathrm{H}_{38} \mathrm{ClN}_{7} \mathrm{O}_{7}: \mathrm{C}, 59.70 ; \mathrm{H}, 5.44 ; \mathrm{N}, 13.92$. Found: C, 59.64; H, 5.49; N, 13.89.

MS $\left(\mathrm{ESI}^{+}\right), \mathrm{m} / \mathrm{z} 742.2[\mathrm{M}+\mathrm{K}]^{+}(100 \%), 726.3[\mathrm{M}+\mathrm{Na}]^{+}(67 \%), 704.3[\mathrm{M}+\mathrm{H}]^{+}(13 \%)$. HRMS Calcd. for $\mathrm{C}_{35} \mathrm{H}_{38} \mathrm{~N}_{7} \mathrm{O}_{7} \mathrm{ClNa}[\mathrm{M}+\mathrm{Na}]^{+}:$726.2419. Found: $726.2435[\mathrm{M}+\mathrm{Na}]^{+}$.

\section{4-Semicarbazone-3(S)-[2-(2-oxo-5-phenyl-3(R)-(4-chloro-2-}

trifluoromethylphenylcarbamoyloxymethyl)-2,3-dihydro-benzo[e][1,4]diazepin-1-yl)acetylamino]-butyric acid tert-butyl ester (15i)

With a similar procedure alcohol $(200 \mathrm{mg}, 0.37 \mathrm{mmol})$ and 4-chloro-2-trifluoromethylphenyl isocyanate (112 $\mu \mathrm{l}, 0.74 \mathrm{mmol})$ gave carbamate $\mathbf{1 5 i}(191 \mathrm{mg}, 68 \%)$.

$[\alpha]^{20}-26.2\left(c=0.23, \mathrm{CHCl}_{3}\right)$

${ }^{1} \mathrm{H}$ NMR (300 MHz, $\left.\mathrm{CDCl}_{3}\right): \delta 9.56$ (bs, 1H), 7.90 (d, 2H, J = $\left.7.6 \mathrm{~Hz}\right), 7.76(\mathrm{~d}, 1 \mathrm{H}, J=8.0$ Hz), 7.60 (d, 2H, J = 6.9 Hz), $7.57-7.09$ (m, 10H), 6.37 (bs, 1H), 5.36 (bs, 1H), $5.08-4.83$ $(\mathrm{m}, 3 \mathrm{H}), 4.66(\mathrm{ABd}, 1 \mathrm{H}, J=15.6 \mathrm{~Hz}), 4.22(\mathrm{ABd}, 1 \mathrm{H}, J=15.6 \mathrm{~Hz}), 4.08(\mathrm{t}, 1 \mathrm{H}, J=6.7 \mathrm{~Hz})$, $2.70-2.53(\mathrm{~m}, 2 \mathrm{H}), 1.41(\mathrm{~s}, 6 \mathrm{H}), 1.27(\mathrm{~s}, 3 \mathrm{H}) ;{ }^{13} \mathrm{C} \mathrm{NMR}\left(75 \mathrm{MHz}, \mathrm{CHCl}_{3}\right): \delta \mathrm{ppm} \mathrm{169.98,}$ 169.94, 169.30, 167.96, 157.89, 153.31, 142.42, 141.30, 138.10, 134.15, 132.79, 132.01, 130.73 , 130.09, 129.71, 129.15, 129.02, 128.24, 126.02, 125.96, 124.87, 124.52, 122.88, 121.50, 81.37, 65.45, 61.69, 52.94, 47.36, 37.53, 27.93, 27.87. Anal. Calcd. for $\mathrm{C}_{35} \mathrm{H}_{35} \mathrm{ClF}_{3} \mathrm{~N}_{7} \mathrm{O}_{7}$ : C, 55.45; H, 4.65; N, 12.93. Found: C, 55.46; H, 4.63; N, 12.96.

MS $\left(\mathrm{ESI}^{+}\right), \mathrm{m} / \mathrm{z} 796.2[\mathrm{M}+\mathrm{K}]^{+}(15 \%), 780.2[\mathrm{M}+\mathrm{Na}]^{+}(100 \%), 758.3[\mathrm{M}+\mathrm{H}]^{+}(62 \%)$. HRMS Calcd. for $\mathrm{C}_{35} \mathrm{H}_{36} \mathrm{~N}_{7} \mathrm{O}_{7} \mathrm{~F}_{3} \mathrm{Cl}[\mathrm{M}+\mathrm{H}]^{+}:$758.2317. Found: $758.2316[\mathrm{M}+\mathrm{H}]^{+}$. 


\section{Phenyl-carbamic acid 1-[(2-hydroxy-5-oxo-tetrahydro-furan-3(S)-ylcarbamoyl)-methyl]-}

2-oxo-5-phenyl-2,3-dihydro-1H-benzo[ $e][1,4]$ diazepin-3(R)-ylmethyl ester (1a)

Semicarbazone 15a $(191 \mathrm{mg}, 0.29 \mathrm{mmol})$ was dissolved in a solution of $25 \%$ TFA in $\mathrm{CH}_{2} \mathrm{Cl}_{2}$ and stirred at room temperature for $6 \mathrm{~h}$. The reaction mixture was concentrated under reduced pressure, the residue was treated with a solution of $\mathrm{MeOH} / \mathrm{AcOH} / 37 \%$ aq. $\mathrm{HCHO}(3 / 1 / 1,10$ $\mathrm{mL}$ ) and stirred at room temperature for $20 \mathrm{~h}$. The reaction mixture was concentrated under vacuum and the resulting residue purified by silica gel chromatography $(5 \% \mathrm{MeOH}, 2 \%$ formic acid in $\mathrm{CH}_{2} \mathrm{Cl}_{2}$ ) to afford $1 \mathbf{a}(66 \mathrm{mg}, 42 \%)$.

$[\alpha]^{20}{ }_{\mathrm{D}}-61.0(c=0.10, \mathrm{MeOH})$

${ }^{1} \mathrm{H}$ NMR (300 MHz, CD $\left.3 \mathrm{OD}\right): \delta 7.84-7.37$ (m, 13H), 7.17 (t, 1H, $\left.J=7.4 \mathrm{~Hz}\right), 5.01(\mathrm{~d}, 2 \mathrm{H}, J$ $=6.6 \mathrm{~Hz}), 4.92-4.75(\mathrm{~m}, 2 \mathrm{H}), 4.66-4.46(\mathrm{~m}, 2 \mathrm{H}), 4.25(\mathrm{t}, 1 \mathrm{H}, J=6.6 \mathrm{~Hz}), 2.94-2.60(\mathrm{~m}$, $2 \mathrm{H}) ;{ }^{13} \mathrm{C}$ NMR (75 MHz, $\left.\mathrm{CD}_{3} \mathrm{OD}\right): \delta 172.39,172.26,170.41,170.20,170.11,169.98$ 155.73, $144.08,144.03,140.18,139.81,133.45,133.37,181.86,131.81,131,41,130.83,130.65$, 130.58, 129.84, 129.38, 125.92, 124.02, 123.37, 119.73, 98.54, 98.18, 65.72, 63.45, 52.53, 52.13, 52.02, 51.80. Anal. Calcd. for $\mathrm{C}_{29} \mathrm{H}_{26} \mathrm{~N}_{4} \mathrm{O}_{7}$ : C, 64.20; H, 4.83; N, 10.33. Found: C, 64.17; H, 4.84; N, 10.36.

MS (ESI'), m/z $573.2[\mathrm{M}-\mathrm{H}+\mathrm{MeOH}]^{-}(17 \%), 541.3[\mathrm{M}-\mathrm{H}]^{-}(100 \%)$.

HRMS calcd. for $\mathrm{C}_{29} \mathrm{H}_{25} \mathrm{~N}_{4} \mathrm{O}_{7}[\mathrm{M}-\mathrm{H}]^{-}=541.1723$. Found: $541.1732[\mathrm{M}-\mathrm{H}]^{-}$.

\section{Naphth-1-yl-carbamic acid 1-[(2-hydroxy-5-oxo-tetrahydro-furan-3(S)-ylcarbamoyl)-} methyl]-2-oxo-5-phenyl-2,3-dihydro-1H-benzo[e][1,4]diazepin-3(R)-ylmethyl ester (1b)

With a similar synthetic procedure and method of purification semicarbazone 15b (189 mg, $0.27 \mathrm{mmol})$ afforded $\mathbf{1 b}(59 \mathrm{mg}, 37 \%)$.

$[\alpha]^{20} \mathrm{D}-70.9(c=0.11, \mathrm{MeOH})$

${ }^{1} \mathrm{H}$ NMR (300 MHz, CD $\left.3 \mathrm{OD}\right): \delta 8.22-8.15(\mathrm{~m}, 1 \mathrm{H}), 8.04-7.95(\mathrm{~m}, 1 \mathrm{H}), 7.67-7.58(\mathrm{~m}$, $12 \mathrm{H}), 7.48-7.42(\mathrm{~m}, 2 \mathrm{H}), 5.10-4.40(\mathrm{~m}, 6 \mathrm{H}), 4.32-4.28(\mathrm{~m}, 1 \mathrm{H}), 2.94-2.60(\mathrm{~m}, 2 \mathrm{H}) ;{ }^{13} \mathrm{C}$ NMR (75 MHz, $\left.\mathrm{CD}_{3} \mathrm{OD}\right): \delta$ 172.45, 172.32, 170.42, 170.29, 170.13, 170.01, 157.24, 144.15, $139.84,135.68,134.63,133.46,133.39,131.86,131.46,130.98,130.84,130.65,129.35$, $129.31,127.08,127.05,126.57,125.94,123.37,123.20,98.61,98.22$, 65.96, 63.45, 52.57, 52.20, 52.06, 51.83. Anal. Calcd. for $\mathrm{C}_{33} \mathrm{H}_{28} \mathrm{~N}_{4} \mathrm{O}_{7}$ : C, 66.88; H, 4.76; N, 9.45. Found: C, $66.92 ; \mathrm{H}, 4.75 ; \mathrm{N}, 9.47$.

MS (ESI $\left.{ }^{-}\right), \mathrm{m} / \mathrm{z} 623.1[\mathrm{M}-\mathrm{H}+\mathrm{MeOH}]^{-}(24 \%), 591.3[\mathrm{M}-\mathrm{H}]^{-}(100 \%), 422.3$ (33\%), 404.3 $(24 \%)$.

HRMS calcd. for $\mathrm{C}_{33} \mathrm{H}_{27} \mathrm{~N}_{4} \mathrm{O}_{7}[\mathrm{M}-\mathrm{H}]^{-}=591.1880$. Found: $591.1898[\mathrm{M}-\mathrm{H}]^{-}$. 
(4-Methoxyphenyl)-carbamic

acid

1-[(2-hydroxy-5-oxo-tetrahydro-furan-3(S)ylcarbamoyl)-methyl]-2-oxo-5-phenyl-2,3-dihydro-1H-benzo[e][1,4]diazepin-3(R)ylmethyl ester (1c)

With a similar synthetic procedure and method of purification semicarbazone 15c $(189 \mathrm{mg}$, $0.28 \mathrm{mmol}$ ) afforded $1 \mathrm{c}(30 \mathrm{mg}, 19 \%)$.

$[\alpha]^{20} \mathrm{D}-35.6(c=0.18, \mathrm{MeOH})$

${ }^{1} \mathrm{H}$ NMR (300 MHz, CD 30 D): $\delta 7.82-7.40$ (m, 10H), 7.05 (d, 1H, J=8.7 Hz), $7.00(\mathrm{~d}, 2 \mathrm{H}, J$ $=8.6 \mathrm{~Hz}), 5.12-4.74(\mathrm{~m}, 4 \mathrm{H}), 4.66-4.38(\mathrm{~m}, 2 \mathrm{H}), 4.23-4.20(\mathrm{~m}, 1 \mathrm{H}), 3.92(\mathrm{~s}, 3 \mathrm{H}), 2.94-$ $2.60(\mathrm{~m}, 2 \mathrm{H}) ;{ }^{13} \mathrm{C}$ NMR $\left(75 \mathrm{MHz}, \mathrm{CD}_{3} \mathrm{OD}\right): \delta 172.42,172.30,170.44,170.33,170.15$, $170.01,160.08,157.22$, 144.07, 144.03, 139.79, 133.39, 131.86, 131.42, 130.99, 129.66, $129.34,125.94,123.38,115.02,98.59,98.21,65.60,63.97,55.85,52.58,52.20,52.05,51.81$. Anal. Calcd. for $\mathrm{C}_{30} \mathrm{H}_{28} \mathrm{~N}_{4} \mathrm{O}_{8}$ : C, 62.93; H, 4.93; N, 9.79. Found: C, 62.92; H, 4.91; N, 9.79. MS (ESI'), m/z $603.3[\mathrm{M}-\mathrm{H}+\mathrm{MeOH}]^{-}(14 \%), 571.3[\mathrm{M}-\mathrm{H}]^{-}(100 \%), 404.4$ (32\%). HRMS calcd. for $\mathrm{C}_{30} \mathrm{H}_{27} \mathrm{~N}_{4} \mathrm{O}_{8}[\mathrm{M}-\mathrm{H}]^{-}=571.1829$. Found: $571.1828[\mathrm{M}-\mathrm{H}]^{-}$.

(4-Chlorophenyl)-carbamic acid 1-[(2-hydroxy-5-oxo-tetrahydro-furan-3(S)ylcarbamoyl)-methyl]-2-oxo-5-phenyl-2,3-dihydro-1H-benzo[e][1,4]diazepin-3(R)ylmethyl ester (1d)

With a similar synthetic procedure and method of purification semicarbazone 15d (193 mg, $0.28 \mathrm{mmol})$ afforded $\mathbf{1 d}(66 \mathrm{mg}, 41 \%)$.

$[\alpha]_{\mathrm{D}}^{20}-45.5(c=0.11, \mathrm{MeOH})$

${ }^{1} \mathrm{H}$ NMR (300 MHz, CD $\left.{ }_{3} \mathrm{OD}\right): \delta 7.82-7.20(\mathrm{~m}, 13 \mathrm{H}), 5.12$ - $4.72(\mathrm{~m}, 4 \mathrm{H}), 4.64-4.40$ (m, $2 \mathrm{H}), 4.24-4.19(\mathrm{~m}, 1 \mathrm{H}), 2.95-2.62(\mathrm{~m}, 2 \mathrm{H}) ;{ }^{13} \mathrm{C} \mathrm{NMR}\left(75 \mathrm{MHz}, \mathrm{CD}_{3} \mathrm{OD}\right): \delta$ 172.40, $172.34,170.35,170.25,170.15,169.95,155.54,144.04,144.00,139.77,139.13,133.45$, $133.38,131.86,131.39,130.96,130.93,130.80$, 130.61, 130.54, 129.75, 129.34, 128.74, 125.93, 123.34, 120.96, 98.57, 98.20, 65.80, 63.40, 52.54, 52.15, 52.03, 51.81. Anal. Calcd. for $\mathrm{C}_{29} \mathrm{H}_{25} \mathrm{ClN}_{4} \mathrm{O}_{7}$ : C, 60.37; H, 4.37; N, 9.71. Found: C, 60.36; H, 4.35; N, 9.72. MS (ESI'), m/z $607.1[\mathrm{M}-\mathrm{H}+\mathrm{MeOH}]^{-}(29 \%), 575.4[\mathrm{M}-\mathrm{H}]^{-}(100 \%), 422.4$ (14\%), 404.5 $(23 \%)$.

HRMS calcd. for $\mathrm{C}_{29} \mathrm{H}_{24} \mathrm{ClN}_{4} \mathrm{O}_{7}[\mathrm{M}-\mathrm{H}]^{-}=575.1334$. Found: $575.1343[\mathrm{M}-\mathrm{H}]^{-}$. 
(4-Fluorophenyl)-carbamic

acid

1-[(2-hydroxy-5-oxo-tetrahydro-furan-3(S)-

ylcarbamoyl)-methyl]-2-oxo-5-phenyl-2,3-dihydro-1H-benzo[ $[e][1,4] \operatorname{diazepin-3(R)-}$

ylmethyl ester (1e)

With a similar synthetic procedure and method of purification semicarbazone 15e $(197 \mathrm{mg}$, $0.29 \mathrm{mmol})$ afforded $1 \mathrm{e}(67 \mathrm{mg}, 41 \%)$.

$[\alpha]_{\mathrm{D}}^{20}-44.0(c=0.10, \mathrm{MeOH})$

${ }^{1} \mathrm{H}$ NMR (300 MHz, CD $\left.3 \mathrm{OD}\right): \delta 7.90-7.29(\mathrm{~m}, 11 \mathrm{H}), 7.16(\mathrm{t}, 2 \mathrm{H}, J=8.4 \mathrm{~Hz}), 5.05-4.63$ $(\mathrm{m}, 4 \mathrm{H}), 4.61-4.32(\mathrm{~m}, 2 \mathrm{H}), 4.24(\mathrm{t}, 1 \mathrm{H}, J=6.7 \mathrm{~Hz}), 3.05-2.53(\mathrm{~m}, 2 \mathrm{H}) ;{ }^{13} \mathrm{C}$ NMR $(75$ $\left.\mathrm{MHz}, \mathrm{CD}_{3} \mathrm{OD}\right): \delta 172.39,172.25,170.36,170.24,170.15,169.98,161.38,158.73,155.80$, $144.11,144.07,139.78,136.37,133.43,133.36,131.82,130.80,130.55,129.64,126.00$, $123.47,123.32,121.36,116.33,116.09,98.53,98.17,65.76,63.42,52.54,52.14,52.02$, 51.79. Anal. Calcd. for $\mathrm{C}_{29} \mathrm{H}_{25} \mathrm{FN}_{4} \mathrm{O}_{7}: \mathrm{C}, 62.14 ; \mathrm{H}, 4.50 ; \mathrm{N}, 10.00$. Found: $\mathrm{C}, 62.12 ; \mathrm{H}, 4.49$; N, 9.99 .

MS (ESI $), \mathrm{m} / \mathrm{z} 591.2[\mathrm{M}-\mathrm{H}+\mathrm{MeOH},]^{-}(21 \%), 559.3$ [M - H] $]^{-}(100 \%), 422.5$ (10\%), 404.4 $(20 \%)$.

HRMS calcd. for $\mathrm{C}_{29} \mathrm{H}_{24} \mathrm{FN}_{4} \mathrm{O}_{7}[\mathrm{M}-\mathrm{H}]^{-}=559.1629$. Found: 559.1616 [M - H] .

(2,4-Difluorophenyl)-carbamic acid 1-[(2-hydroxy-5-oxo-tetrahydro-furan-3(S)ylcarbamoyl)-methyl]-2-oxo-5-phenyl-2,3-dihydro-1H-benzo[e][1,4]diazepin-3(R)ylmethyl ester (1f)

With a similar synthetic procedure and method of purification semicarbazone $\mathbf{1 5 f}$ (196 $\mathrm{mg}$, $0.28 \mathrm{mmol})$ afforded $\mathbf{1 f}(64 \mathrm{mg}, 39 \%)$.

$[\alpha]^{20} \mathrm{D}-5.0(c=0.58, \mathrm{MeOH})$

${ }^{1} \mathrm{H}$ NMR (300 MHz, CD $\left.3 \mathrm{OD}\right): \delta 8.05-7.93(\mathrm{~m}, 1 \mathrm{H}), 7.85-7.72(\mathrm{~m}, 3 \mathrm{H}), 7.70(\mathrm{~d}, 1 \mathrm{H}, J=8.1$ Hz) $7.66(\mathrm{~d}, 1 \mathrm{H}, J=7.3 \mathrm{~Hz}), 7.58(\mathrm{t}, 2 \mathrm{H}, J=7.7 \mathrm{~Hz}), 7.50-7.40(\mathrm{~m}, 2 \mathrm{H}), 7.18-7.04(\mathrm{~m}$, 2H), $5.03(\mathrm{~d}, 2 \mathrm{H}, J=6.5 \mathrm{~Hz}), 4.93-4.75(\mathrm{~m}, 2 \mathrm{H}), 4.66-4.46(\mathrm{~m}, 2 \mathrm{H}), 4.26(\mathrm{t}, 1 \mathrm{H}, J=6.5$ $\mathrm{Hz}), 2.95$ - $2.62(\mathrm{~m}, 2 \mathrm{H}) ;{ }^{13} \mathrm{C}$ NMR $\left(75 \mathrm{MHz}, \mathrm{CD}_{3} \mathrm{OD}\right): \delta 172.44,172.31,170.37,170.27$, $170.09,169.96,161.82$, 161.68, 158.90, 158.76, 156.79, 156.64, 156.02, 154.04, 153.89, $144.09,144.04,139.80,133.45,133.38,131.87,131.42$, 130.94, 130.62, 130.55, 129.34, $125.90,123.32$, 112.03, 111.99, 111.79, 111.75, 104.95, 104.68, 104.65, 104.39, 98.69, 98.16, 66.10, 63.31, 52.52, 52.13, 52.01, 51.79. Anal. Calcd. for $\mathrm{C}_{29} \mathrm{H}_{24} \mathrm{~F}_{2} \mathrm{~N}_{4} \mathrm{O}_{7}$ : C, 60.21; H, 4.18; N, 9.68. Found: C, 60.19; H, 4.15; N, 9.69.

MS (ESI $\left.{ }^{-}\right), \mathrm{m} / \mathrm{z} 577.2[\mathrm{M}-\mathrm{H}]^{-}(100 \%)$.

HRMS Calcd. for $\mathrm{C}_{29} \mathrm{H}_{23} \mathrm{~N}_{4} \mathrm{O}_{7} \mathrm{~F}_{2}[\mathrm{M}-\mathrm{H}]^{-}: 577.1535$. Found: $577.1545[\mathrm{M}-\mathrm{H}]^{-}$. 
(2-Bromo-4,6-difluorophenyl)-carbamic acid 1-[(2-hydroxy-5-oxo-tetrahydro-furan3(S)-ylcarbamoyl)-methyl]-2-oxo-5-phenyl-2,3-dihydro-1H-benzo[e][1,4]diazepin-3(R)ylmethyl ester (1g)

With a similar synthetic procedure and method of purification semicarbazone $15 \mathrm{~g}$ (228 $\mathrm{mg}$, $0.30 \mathrm{mmol})$ afforded $\mathbf{1 g}(78 \mathrm{mg}, 40 \%)$.

$[\alpha]^{20} \mathrm{D}-56.8(c=0.35, \mathrm{MeOH})$

${ }^{1} \mathrm{H}$ NMR (300 MHz, $\left.\mathrm{CD}_{3} \mathrm{OD}\right): \delta 7.86-7.63(\mathrm{~m}, 5 \mathrm{H}), 7.59$ (t, 2H, J= 7.4 Hz), $7.51-7.41(\mathrm{~m}$, $3 \mathrm{H}), 7.27(\mathrm{td}, 1 \mathrm{H}, J=9.4 \mathrm{~Hz}$ and $J=2.6 \mathrm{~Hz}), 5.05-4.99(\mathrm{~m}, 2 \mathrm{H}), 4.91-4.70(\mathrm{~m}, 2 \mathrm{H}), 4.68-$ $4.46(\mathrm{~m}, 2 \mathrm{H}), 4.30-4.20(\mathrm{~m}, 1 \mathrm{H}), 2.94-2.56(\mathrm{~m}, 2 \mathrm{H}) ;{ }^{13} \mathrm{C} \mathrm{NMR}\left(75 \mathrm{MHz}, \mathrm{CD}_{3} \mathrm{OD}\right): \delta$ $172.41,172.28,170.25,170.15,170.05,169.93,163.87,163.73,161.98,161.83,161.10$, $160.96,159.18,159.03,156.92$, 144.10, 144.07, 139.75, 133.43, 133.38, 131.86, 131.38, $131.00,130.66$, 130.59, 129.30, 125.95, 123.13, 116.94, 116.90, 116.66, 116.62, 105.43, $105.14,104.85,98.52,98.16,66.60,63.35,52.50,52.11,51.90,51.69$. Anal. Calcd. for $\mathrm{C}_{29} \mathrm{H}_{23} \mathrm{BrF}_{2} \mathrm{~N}_{4} \mathrm{O}_{7}$ : C, 52.98; H, 3.53; N, 8.52. Found: C, 53.02; H, 3.54; N, 8.52.

MS (ESI'), m/z 655.0 [M - H] $]^{-}(18 \%), 422.1$ (100\%), 404.1 (22\%).

HRMS Calcd. for $\mathrm{C}_{29} \mathrm{H}_{22} \mathrm{~N}_{4} \mathrm{O}_{7} \mathrm{~F}_{2} \mathrm{Br}[\mathrm{M}-\mathrm{H}]^{-}: 655.0640$. Found: $655.0652[\mathrm{M}-\mathrm{H}]^{-}$.

(4-Chloro-2-methylphenyl)-carbamic acid 1-[(2-hydroxy-5-oxo-tetrahydro-furan-3(S)ylcarbamoyl)-methyl]-2-oxo-5-phenyl-2,3-dihydro-1 $H$-benzo[ $[e][1,4] \operatorname{diazepin-3}(R)$ ylmethyl ester (1h)

With a similar synthetic procedure and method of purification semicarbazone 15h (172 mg, $0.24 \mathrm{mmol})$ afforded $\mathbf{1 h}(56 \mathrm{mg}, 39 \%)$.

$[\alpha]^{20}{ }_{\mathrm{D}}-58.1(c=0.21, \mathrm{MeOH})$

${ }^{1} \mathrm{H}$ NMR (300 MHz, $\left.\mathrm{CD}_{3} \mathrm{OD}\right): \delta 7.85-7.62(\mathrm{~m}, 6 \mathrm{H}), 7.59(\mathrm{t}, 2 \mathrm{H}, J=7.6 \mathrm{~Hz}), 7.49-7.42(\mathrm{~m}$, 2H), $7.35(\mathrm{~s}, 1 \mathrm{H}), 7.31(\mathrm{dd}, 1 \mathrm{H}, J=8.5 \mathrm{~Hz}$ and $J=2.5 \mathrm{~Hz}), 5.02(\mathrm{~d}, 2 \mathrm{H}, J=6.5 \mathrm{~Hz}), 4.93-$ $4.71(\mathrm{~m}, 2 \mathrm{H}), 4.67-4.44(\mathrm{~m}, 2 \mathrm{H}), 4.25(\mathrm{t}, 1 \mathrm{H}, J=6.5 \mathrm{~Hz}), 2.95-2.60(\mathrm{~m}, 2 \mathrm{H}), 2.38(\mathrm{~s}, 3 \mathrm{H})$; ${ }^{13} \mathrm{C}$ NMR (75 MHz, CD $\left.3 \mathrm{OD}\right): \delta 172.40,172.27,170.40,170.30,170.07,169.94,156.55$, $144.11,144.07,139.79,136.28,133.45,133.38,131.87,131.39,131.10,130.94,130.80$, $130.62,130.55,129.34,127.23,125.93,123.36$, 98.56, 98.19, 65.98, 63.38, 52.54, 52.15, 52.02, 51.71, 17.89. Anal. Calcd. for $\mathrm{C}_{30} \mathrm{H}_{27} \mathrm{ClN}_{4} \mathrm{O}_{7}$ : C, 60.97; H, 4.60; N, 9.48. Found: C, $60.93 ; \mathrm{H}, 4.62 ; \mathrm{N}, 9.51$.

MS (ESI'), m/z 589.1 [M - H] $]^{-}(100 \%), 422.1$ (10\%), 404.1 (11\%).

HRMS Calcd. for $\mathrm{C}_{30} \mathrm{H}_{26} \mathrm{~N}_{4} \mathrm{O}_{7} \mathrm{Cl}[\mathrm{M}-\mathrm{H}]^{-}: 589.1490$. Found: 589.1494 [M - H] . 
(4-Chloro-2-trifluoromethylphenyl)-carbamic acid 1-[(2-hydroxy-5-oxo-tetrahydrofuran-3(S)-ylcarbamoyl)-methyl]-2-oxo-5-phenyl-2,3-dihydro-1H-benzo[ $e][1,4]$ diazepin3(R)-ylmethyl ester (1i)

With a similar synthetic procedure and method of purification semicarbazone 15i (191 mg, $0.25 \mathrm{mmol})$ afforded $\mathbf{1 i}(62 \mathrm{mg}, 38 \%)$.

$[\alpha]^{20}{ }_{\mathrm{D}}-56.2(c=0.29, \mathrm{MeOH})$

${ }^{1} \mathrm{H}$ NMR (300 MHz, $\left.\mathrm{CD}_{3} \mathrm{OD}\right): \delta 7.91-7.87(\mathrm{~m}, 1 \mathrm{H}), 7.85-7.73(\mathrm{~m}, 5 \mathrm{H}), 7.70(\mathrm{~d}, 1 \mathrm{H}, J=7.9$ Hz), $7.67(\mathrm{~d}, 1 \mathrm{H}, J=7.1 \mathrm{~Hz}), 7.59(\mathrm{t}, 2 \mathrm{H}, J=7.6 \mathrm{~Hz}), 7.50-7.40(\mathrm{~m}, 2 \mathrm{H}), 5.07-4.97(\mathrm{~m}$, 2H), $4.92-4.71(\mathrm{~m}, 2 \mathrm{H}), 4.67-4.42(\mathrm{~m}, 2 \mathrm{H}), 4.26(\mathrm{t}, 1 \mathrm{H}, J=6.4 \mathrm{~Hz}), 2.98-2.59(\mathrm{~m}, 2 \mathrm{H})$; ${ }^{13} \mathrm{C}$ NMR (75 MHz, CD 3 OD): $\delta 172.48,172.36,170.37,170.27,170.05,169.93,156.44$, $144.09,144.05,139.81,135.70,133.97,133.45,133.39,132.20,131.87,131.43,130.94$, $130.62,130.56,129.33,127.23,127.17,125.94,125.79,123.47,123.34,122.77,98.57,98.20$, 66.37, 63.21, 52.53, 52.15, 52.00, 51.77. Anal. Calcd. for $\mathrm{C}_{30} \mathrm{H}_{24} \mathrm{ClF}_{3} \mathrm{~N}_{4} \mathrm{O}_{7}: \mathrm{C}, 55.87 ; \mathrm{H}, 3.75$; N, 8.69. Found: C, 55.88; H, 3.73; N, 8.71.

MS (ESI $\left.{ }^{-}\right), \mathrm{m} / \mathrm{z} 681.0[\mathrm{M}-2 \mathrm{H}+\mathrm{K}]^{-}(23 \%), 643.1[\mathrm{M}-\mathrm{H}]^{-}(27 \%), 442.1$ (100\%), 422.1 (14\%), $194.0(21 \%)$.

HRMS Calcd. for $\mathrm{C}_{30} \mathrm{H}_{23} \mathrm{~N}_{4} \mathrm{O}_{7} \mathrm{~F}_{3} \mathrm{Cl}[\mathrm{M}-\mathrm{H}]^{-}: 643.1207$. Found: 643.1218 [M - H] . 


\section{Synthesis of compound $\mathbf{1 j}$}

Compound $\mathbf{1 j}$ was synthesized following the procedures reported above for its diasteromer $\mathbf{1 i}$, starting from L-serine methyl ester hydrochloride. Herein, we report the analytical and spectral data of the intermediates obtained after the coupling of the enantiomer of 9 with the aspartyl aldehyde building block.

\section{3(S)-\{2-[((3S)-(tert-Butyl-dimethyl-silanyloxymethyl)-2-oxo-5-phenyl-2,3-dihydro-} benzo $[e][1,4]$ diazepin-1-yl]-acetylamino\}-4-semicarbazone-butyric acid tert-butyl ester $[\alpha]^{20}{ }_{\mathrm{D}}+29.5\left(c=4.50, \mathrm{CHCl}_{3}\right)$

${ }^{1} \mathrm{H}$ NMR (300 MHz, $\left.\mathrm{CDCl}_{3}\right): \delta$ ppm 9.58 (bs, 1H), 7.72 (d, 1H, J=8.0 Hz), $7.61-7.15$ (m, 9H), $7.06(\mathrm{~d}, 1 \mathrm{H}, J=2.2 \mathrm{~Hz}), 6.09-5.55(\mathrm{bs}, 2 \mathrm{H}), 4.93-4.82(\mathrm{~m}, 1 \mathrm{H}), 4.64(\mathrm{ABd}, 1 \mathrm{H}, J=$ $15.7 \mathrm{~Hz}), 4.52-4.45(\mathrm{~m}, 1 \mathrm{H}), 4.32-4.24(\mathrm{~m}, 1 \mathrm{H}), 4.23(\mathrm{ABd}, 1 \mathrm{H}, J=15.7 \mathrm{~Hz}), 3.80(\mathrm{t}, 1 \mathrm{H}$, $J=6.3 \mathrm{~Hz}), 2.71-2.45(\mathrm{~m}, 2 \mathrm{H}), 1.36(\mathrm{~s}, 9 \mathrm{H}), 0.88(\mathrm{~s}, 9 \mathrm{H}), 0.11(\mathrm{~s}, 3 \mathrm{H}), 0.09(\mathrm{~s}, 3 \mathrm{H}) ;{ }^{13} \mathrm{C}$ NMR (75 MHz, $\mathrm{CHCl}_{3}$ ): $\delta$ ppm 169.86, 169.71, 169.30, 167.87, 157.62, 142.47, 140.80, $138.41,131.78,130.52$, 130.07, 129.65, 129.47, 128.18, 124.80, 122.71, 81.34, 65.12, 63.85, 52.43, 47.24, 37.75, 27.93, 22.88, 18.376 - 5.19. Anal. Calcd. for $\mathrm{C}_{33} \mathrm{H}_{46} \mathrm{~N}_{6} \mathrm{O}_{6} \mathrm{Si} \cdot 0.33 \mathrm{H}_{2} \mathrm{O} \cdot 0.33 \mathrm{MeOH}: \mathrm{C}, 59.98 ; \mathrm{H}, 7.25 ; \mathrm{N}, 12.59$. Found: C, 59.96; H, 7.32; N, 12.61 .

MS $\left(\mathrm{ESI}^{+}\right), \mathrm{m} / \mathrm{z} 673.3[\mathrm{M}+\mathrm{Na}]^{+}(100 \%), 651.3[\mathrm{M}+\mathrm{H}]^{+}(32 \%)$.

\section{3(S)-[2-((3S)-Hydroxymethyl-2-oxo-5-phenyl-2,3-dihydro-benzo[e][1,4]diazepin-1-yl)-} acetylamino]-4-semicarbazone-butyric acid tert-butyl ester

$[\alpha]^{20} \mathrm{D}+11.3\left(c=1.60, \mathrm{CHCl}_{3}\right)$

${ }^{1} \mathrm{H}$ NMR (300 MHz, $\mathrm{CDCl}_{3}$ ): $\delta$ ppm 9.38 (bs, 1H), 8.14 (d, 1H, J=8.4 Hz), $7.63-7.19$ (m, $10 \mathrm{H}), 6.12$ (bs, 2H), $5.03-4.94(\mathrm{~m}, 1 \mathrm{H}), 4.75(\mathrm{ABd}, 1 \mathrm{H}, J=15.6 \mathrm{~Hz}), 4.50-4.39(\mathrm{~m}, 1 \mathrm{H})$, $4.28(\mathrm{ABd}, 1 \mathrm{H}, J=15.6 \mathrm{~Hz}), 4.22-4.15(\mathrm{~m}, 1 \mathrm{H}), 3.90$ (t, 1H, $J=6.6 \mathrm{~Hz}), 3.77$ (bs, 1H), 2.70

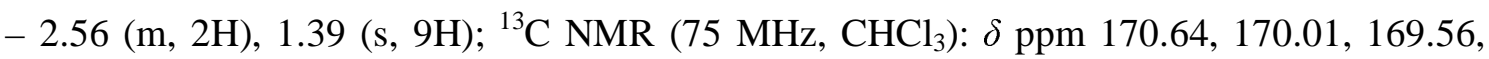
$168.99,157.94,142.66,141.95,138.32,138.23$, 131.95, 130.51, 129.84, 129.62, 129.05, $128.15,124.79,122.91,81.13,64.00,62.39,53.38,47.35,36.65,27.93$. Anal. Calcd. for $\mathrm{C}_{27} \mathrm{H}_{32} \mathrm{~N}_{6} \mathrm{O}_{6} \cdot 1.0 \mathrm{H}_{2} \mathrm{O} \cdot 0.5 \mathrm{MeOH}: \mathrm{C}, 57.88 ; \mathrm{H}, 6.36 ; \mathrm{N}, 14.73$. Found: C, 57.97; H, 6.24; $\mathrm{N}$, 14.74 .

MS $\left(\mathrm{ESI}^{+}\right), \mathrm{m} / \mathrm{z} 559.1[\mathrm{M}+\mathrm{Na}]^{+}(64 \%), 537.1[\mathrm{M}+\mathrm{H}]^{+}(12 \%), 242.4(100 \%), 186.3(50 \%)$. 


\section{4-Semicarbazone-3(S)-[2-(2-oxo-5-phenyl-3(S)-(4-chloro-2-}

trifluoromethylphenylcarbamoyloxymethyl)-2,3-dihydro-benzo[e][1,4]diazepin-1-yl)acetylamino]-butyric acid tert-butyl ester.

$[\alpha]_{\mathrm{D}}^{20}+4.3\left(c=1.15, \mathrm{CHCl}_{3}\right)$

${ }^{1} \mathrm{H}$ NMR (300 MHz, $\left.\mathrm{CDCl}_{3}\right): \delta 8.59(\mathrm{bs}, 1 \mathrm{H}), 8.08(\mathrm{~d}, 2 \mathrm{H}, J=8.1 \mathrm{~Hz}), 7.64-7.24(\mathrm{~m}, 11 \mathrm{H})$, 7.19 (bs, 1H), 7.00 (d, 1H, J=2.2 Hz), 6.33 (bs, 1H), 5.40 (bs, 1H), $5.06-4.83$ (m, 3H), 4.73 $(\mathrm{ABd}, 1 \mathrm{H}, J=15.7 \mathrm{~Hz}), 4.25(\mathrm{ABd}, 1 \mathrm{H}, J=15.7 \mathrm{~Hz}), 4.20(\mathrm{t}, 1 \mathrm{H}, J=6.7 \mathrm{~Hz}), 2.77-2.57(\mathrm{~m}$,

2H), 1.42 (s, 3H), 1.35 (s, 6H); ${ }^{13} \mathrm{C}$ NMR (75 MHz, $\left.\mathrm{CHCl}_{3}\right): \delta \mathrm{ppm} 170.02,169.99,169.27$, $167.94,157.91,153.30,142.42$, 141.30, 138.10, 134.17, 132.76, 132.00, 130.69, 130.09, $129.69,129.15,129.04,128.27,126.02$, 125.99, 124.86, 124.52, 122.89, 121.53, 81.30, 65.41, 61.72, 52.90, 47.39, 37.59, 27.94, 27.87. Anal. Calcd. for $\mathrm{C}_{35} \mathrm{H}_{35} \mathrm{ClF}_{3} \mathrm{~N}_{7} \mathrm{O}_{7}: \mathrm{C}, 55.45 ; \mathrm{H}, 4.65$; $\mathrm{N}, 12.93$. Found: $\mathrm{C}, 55.43 ; \mathrm{H}, 4.61 ; \mathrm{N}, 12.97$.

MS $\left(\mathrm{ESI}^{+}\right), \mathrm{m} / \mathrm{z} 796.2[\mathrm{M}+\mathrm{K}]^{+}(17 \%), 780.2[\mathrm{M}+\mathrm{Na}]^{+}(100 \%), 758.3[\mathrm{M}+\mathrm{H}]^{+}(72 \%)$.

HRMS Calcd. for $\mathrm{C}_{35} \mathrm{H}_{36} \mathrm{~N}_{7} \mathrm{O}_{7} \mathrm{~F}_{3} \mathrm{Cl}[\mathrm{M}+\mathrm{H}]^{+}:$758.2317. Found: $758.2318[\mathrm{M}+\mathrm{H}]^{+}$.

(4-Chloro-2-trifluoromethylphenyl)-carbamic acid 1-[(2-hydroxy-5-oxo-tetrahydrofuran-3(S)-ylcarbamoyl)-methyl]-2-oxo-5-phenyl-2,3-dihydro-1H-benzo[ $e][1,4]$ diazepin3(S)-ylmethyl ester (1j)

$[\alpha]_{\mathrm{D}}^{20}+5.0(c=1.06, \mathrm{MeOH})$

${ }^{1} \mathrm{H}$ NMR (300 MHz, CD $\left.3 \mathrm{OD}\right): \delta 7.90-7.85(\mathrm{~m}, 1 \mathrm{H}), 7.85-7.72(\mathrm{~m}, 5 \mathrm{H}), 7.72(\mathrm{~d}, 1 \mathrm{H}, J=8.0$ $\mathrm{Hz}), 7.66(\mathrm{~d}, 1 \mathrm{H}, J=7.1 \mathrm{~Hz}), 7.58(\mathrm{t}, 2 \mathrm{H}, J=7.6 \mathrm{~Hz}), 7.50-7.42(\mathrm{~m}, 2 \mathrm{H}), 5.10-4.99$ (m, 2H), $4.90-4.73(\mathrm{~m}, 2 \mathrm{H}), 4.66-4.41(\mathrm{~m}, 2 \mathrm{H}), 4.22(\mathrm{t}, 1 \mathrm{H}, J=6.6 \mathrm{~Hz}), 2.95-2.61(\mathrm{~m}, 2 \mathrm{H})$; ${ }^{13} \mathrm{C}$ NMR (75 MHz, CD $\left.{ }_{3} \mathrm{OD}\right): \delta 172.52,172.39,170.31,170.31,170.02,169.92,156.44$, $144.07,144.05,139.80,135.70,133.96,133.41,133.37,132.20,131.87,131.41,130.96$, $130.62,130.55,129.32,127.23,127.16,125.92,125.82,123.47,123.34,122.77,98.59,98.21$, 66.38, 63.21, 52.55, 52.18, 52.02, 51.77. Anal. Calcd. for $\mathrm{C}_{30} \mathrm{H}_{24} \mathrm{ClF}_{3} \mathrm{~N}_{4} \mathrm{O}_{7}: \mathrm{C}, 55.87 ; \mathrm{H}, 3.75$; N, 8.69. Found: C, 55.89; H, 3.77; N, 8.68.

MS (ESI $), \mathrm{m} / \mathrm{z} 681.0\left[\mathrm{M}-2 \mathrm{H}+\mathrm{K}^{-}(25 \%), 643.1[\mathrm{M}-\mathrm{H}]^{-}(31 \%), 442.1(100 \%), 422.1\right.$ (10\%), $194.0(19 \%)$.

HRMS Calcd. for $\mathrm{C}_{30} \mathrm{H}_{23} \mathrm{~N}_{4} \mathrm{O}_{7} \mathrm{~F}_{3} \mathrm{Cl}[\mathrm{M}-\mathrm{H}]^{-}: 643.1207$. Found: 643.1216 [M - H] . 


\section{$\underline{\text { Biological Section }}$}

\section{Gene cloning of falcipain-2A and $2 B$}

The mature domain of FP-2B including one amino acid of the prodomain and the mature domain of FP-2A were cloned by nested PCR from P. falciparum 3D7 strain genomic DNA. Primers used for FP-2B were, for first PCR, FP2BF (5'AACAATAACAATAATACTTCATC-3') and FP-2BR (5'CTTTTAAAATACTAAGCTTATATTTATTC-3') and, for second PCR, FP-2B.1F (5'CGCGGATCCGATCAAATAAATTATGAC-3') and FP-2BR. Primers for FP-2A were, for the first PCR, FP-2AF (5'-CGAAGGTAATAACAACAATAATG-3') and FP-2AR (5'CTTTTAAAATACTAAGCTTATATTTATTC-3') and, for the second PCR, FP-2A.1F (5'CGGGATCCCAAATGAATTATGAAGAAG-3') and FP-2AR (BamHI and HindIII sites are italicized). PCRs were performed using recombinant Taq polymerase (Invitrogen), under conditions of $30 \mathrm{~s}$ at $94^{\circ} \mathrm{C}, 30 \mathrm{~s}$ at $53^{\circ} \mathrm{C}$, and $60 \mathrm{~s}$ at $72^{\circ} \mathrm{C}$ for 25 cycles. The amplified fragments were purified with the Nucleospin Extraction Kit (Clontech) and cloned into pCR2.1 TOPO vector (Invitrogen). The nucleotide sequences were confirmed by DNA sequencing. For the expression of Maltose Binding Protein (MBP) the amplified inserts were cloned into pMAL-c2× vector (New England Biolabs) using BamHI and HindIII sites.

\section{Expression and Purification of MBP-FP-2A and MBP-FP-2B}

Seed culture of $5 \mathrm{ml}$ was grown overnight and diluted with $500 \mathrm{ml}$ of LB medium containing $100 \mu \mathrm{g} / \mathrm{ml}$ ampicillin and further incubated at $37^{\circ} \mathrm{C}$ up to a cell density of $0.6-0.8$ (absorbance at $600 \mathrm{~nm}$ ). The final concentration of $0.2 \mathrm{mM}$ isopropyl-1-thio-galactoside (IPTG) was added to induce the expression, and the culture was further incubated for $12 \mathrm{~h}$ at $25^{\circ} \mathrm{C}$. Cells were harvested by centrifugation and lysed by sonication in the lysis buffer (20 $\mathrm{mM}$ Tris- $\mathrm{HCl}, \mathrm{pH} 8.0,150 \mathrm{mM} \mathrm{NaCl}$ ), and the cell free extract was prepared by centrifugation. The MBP-FP-2A and MBP-FP-2B fusion protein was purified by amylose affinity chromatography (New England Biolabs). MBP-tag was cleaved with an appropriate amount of Factor Xa protease (New England Biolabs) at $4{ }^{\circ} \mathrm{C}$ for $24-36 \mathrm{~h}$. The cleaved FPs were separated from MBP using Superdex 75 gel filtration and Mono-Q 5/50 GL (GE Healthcare). To improve the expression and activity of purified FP-2A and FP-2B enzymes, induction conditions of $37^{\circ} \mathrm{C}$ for $5 \mathrm{~h}$ were also incorporated. After the elution of MBP-FPs from the amylose column, Factor Xa digestion was carried out at $4^{\circ} \mathrm{C}$ for $24-36 \mathrm{~h}$. The 
activity of the protein was measured by fluorometric quantification of the cleavage of fluorescent substrate, Benzyloxycarbonyl-Phe-Arg- 7-amino-4 methyl coumarin (Z-phe-Arg$\mathrm{AMC})$.

\section{Assays of Falcipain-2A and Falcipain-2B Activity}

FP-2A and FP-2B activities were assayed by the standard one-dimensional gelatine-substrate SDS-PAGE zymography, followed by fluorometric measurements of specific substrate hydrolysis with peptidyl aminomethylcoumarins (AMC). For substrate gel analysis, protein samples were mixed with non-reducing SDS-PAGE sample buffer lacking 2-mercaptoethanol and electrophoresed in a polyacrylamide gel copolymerized with $0.1 \%$ gelatin. The gel was then washed twice (30 min, RT) with $2.5 \%$ Triton X-100 and incubated overnight at $37{ }^{\circ} \mathrm{C}$ in $100 \mathrm{mM}$ NaOAc, 10 mM DTT, pH 5.5, before staining with Coomassie Blue.

Fluorimetric assays of recombinant FPs activity and their inhibition were carried out with peptide substrate to compare the substrate specificities of the proteases. Enzymes activity was assessed by measuring the hydrolysis of the substrate benzyloxycarbonyl-Leu-Arg-7-amino4-methylcoumarin (Z-Leu-Arg-AMC). Briefly, $5 \mu$ l of enzyme was incubated in $55 \mu$ assay buffer (100 mM NaOAc, $10 \mathrm{mM}$ DTT, pH 5.5 or 7.0 ) for $15 \mathrm{~min}$ at room temperature before the addition of $40 \mu \mathrm{l}$ of the fluorescence substrate $(25 \mu \mathrm{l})$. The release of 7-amino-4-methyl coumarin (AMC) was monitored (excitation $355 \mathrm{~nm}$; emission $460 \mathrm{~nm}$ ) over $30 \mathrm{~min}$ at RT with a Labsystems Fluoroskan II spectrofluorometer. The rate of hydrolysis of Z-Leu-ArgAMC (increase in fluorescence/time) in the presence of inhibitors was compared with the rate of hydrolysis in negative controls incubated with an equivalent volume of DMSO and with positive controls incubated with MDL 28170, a standard inhibitor of papain-like family cysteine proteases bearing an aldehyde moiety. 